\title{
Review Article \\ Vascular Tissue Engineering: Recent Advances in Small Diameter Blood Vessel Regeneration
}

\author{
Valentina Catto, ${ }^{1,2}$ Silvia Farè, ${ }^{1,2}$ Giuliano Freddi, ${ }^{3}$ and Maria Cristina Tanzi ${ }^{1,2}$ \\ ${ }^{1}$ Laboratorio Biomateriali, Dipartimento di Chimica, Materiali e Ingegneria Chimica "G. Natta”, Politecnico di Milano, \\ Piazza L. da Vinci 32, 20133 Milano, Italy \\ ${ }^{2}$ Local Unit Politecnico di Milano, INSTM, Via G. Giusti 9, 50121 Firenze, Italy \\ ${ }^{3}$ INNOVHUB-SSI, Divisione Stazione Sperimentale per la Seta, Via G. Colombo 83, 20133 Milano, Italy
}

Correspondence should be addressed to Silvia Farè; silvia.fare@polimi.it

Received 29 October 2013; Accepted 21 November 2013; Published 27 January 2014

Academic Editors: B. Hambly and M. Zhang

Copyright (c) 2014 Valentina Catto et al. This is an open access article distributed under the Creative Commons Attribution License, which permits unrestricted use, distribution, and reproduction in any medium, provided the original work is properly cited.

Cardiovascular diseases are the leading cause of mortality around the globe. The development of a functional and appropriate substitute for small diameter blood vessel replacement is still a challenge to overcome the main drawbacks of autografts and the inadequate performances of synthetic prostheses made of polyethylene terephthalate (PET, Dacron) and expanded polytetrafluoroethylene (ePTFE, Goretex). Therefore, vascular tissue engineering has become a promising approach for small diameter blood vessel regeneration as demonstrated by the increasing interest dedicated to this field. This review is focused on the most relevant and recent studies concerning vascular tissue engineering for small diameter blood vessel applications. Specifically, the present work reviews research on the development of tissue-engineered vascular grafts made of decellularized matrices and natural and/or biodegradable synthetic polymers and their realization without scaffold.

\section{Introduction}

Cardiovascular diseases are the leading cause of death around the world. In 2008, 17.3 million people died from cardiovascular related reasons; specifically 7.3 million were due to coronary heart disease [1]. Currently, in the United States $17 \%$ of overall national health expenditures is linked with cardiovascular diseases [2].

Bypass surgeries are commonly performed to allow the peripheral or coronary revascularization. To date, autografts remain the standard clinical approach for the replacement of small diameter blood vessels (inner diameter (ID) < $6 \mathrm{~mm}$ ). Nevertheless, autografts (such as saphenous vein, arm vein, mammalian artery, or radial artery $[3,4]$ ) show some drawbacks: considerable morbidity associated with autologous harvest and scarce availability due to diseases or previous organ harvesting $[4,5]$. Arterial autografts are more indicated for coronary by-pass surgeries due to their higher mechanical properties [6]; internal mammary artery showed a higher patency rate than saphenous vein $(85 \%$ versus $61 \%$, after 10 years) [7]. Synthetic materials, for example, polyethylene terephthalate (PET) and expanded polytetrafluoroethylene (ePTFE), are successfully used for the replacement of medium-large diameter blood vessels (ID > $6 \mathrm{~mm}$ ), when high blood flow and low resistance conditions prevail $[3,4,8]$. However, synthetic grafts used for belowthe-knee vascular by-pass and coronary by-pass (ID $<6 \mathrm{~mm}$ ) fail for unacceptable patency rates in the long term. Patency of ePTFE prostheses is $40-50 \%$ when used to bypass the proximal popliteal artery at 5 years and $20 \%$ when used for infrapopliteal bypass at 3 years [3]. The use of PET or ePTFE for small diameter blood vessels leads to several complications like aneurysm, intimal hyperplasia, calcification, thrombosis, infection, and lack of growth potential for pediatric applications $[3,4,9]$. These drawbacks are mainly correlated to the regeneration of a nonfunctional endothelium and a mismatch between the mechanical properties of grafts and native blood vessels $[3,5,6]$. A comparison 
between the compliance and the elastic modulus of synthetic prostheses and those of native vessels is reported in Table 1.

Causes of graft failure may be classified into early, midterm, and late $[10,11]$. Early failures (within 30 days after the implantation) are related to technical complications, flow disturbances, or acute thrombosis $[10,11]$. Midterm failures (3 months to 2 years after the implantation) consist of lumen occlusion due to intimal hyperplasia, while late failures $(>2$ years) are related to atherosclerotic disease $[10,11]$.

With the aim to improve the scarce patency of synthetic grafts, Deutsch et al. [12] developed a procedure for the autologous in vitro endothelialization of ePTFE prostheses (ID = 6-7 mm). Specifically, the inner side of ePTFE prostheses was coated with fibrin to allow for seeding of autologous ECs in in vitro rotating conditions; after about 9 days of in vitro culture, 341 grafts were implanted as infrainguinal bypass in 310 patients [12]. During 15 years of clinical use, endothelialized ePTFE prostheses showed the presence of endothelium 2-4 years after the surgery and a patency rate similar to vein grafts [12]. The patency rate of $7 \mathrm{~mm}$ prostheses was significantly higher than that of $6 \mathrm{~mm}$ grafts (78\% versus $62 \%$ at 5 years, $71 \%$ versus $55 \%$ at 10 years) [12]. Nevertheless, vascular tissue engineering has become a promising approach to overcome the limits of autografts (e.g., morbidity and scarce availability) and the inappropriate properties of synthetic grafts.

This review summarizes the most relevant and recent studies on vascular tissue engineering for small diameter blood vessel regeneration, focusing on the development of scaffolds made of decellularized matrices and natural and/or biodegradable synthetic polymers and on the realization of tissue-engineered vascular grafts (TEVGs) without scaffold (Figure 1).

\section{Vascular Tissue Engineering}

As reported by Couet et al. [6], vascular tissue engineering "aims to apply the principles of engineering and life sciences towards the development of a vascular construction that demonstrates biological and mechanical properties as close as possible to those of a native vessel".

The requirements of an ideal tissue-engineered vascular graft (TEVG), with both large or small diameter, are summarized in Table $2[3,5,13,14]$. Among all requirements for an ideal TEVG (Table 2), the strictest requisites are correlated to the regeneration of a functional endothelium and the similarity between the mechanical proprieties of TEVG and natural blood vessels. These two requirements are related to the failure of PET and ePTFE prostheses for small caliber vessels.

The basic strategy for vascular tissue engineering consists of the design and the production of appropriate scaffolds for vascular cell adhesion, proliferation, and differentiation and the choice of cell type. For human applications, the ideal cells should be nonimmunogenic, functional, and easy to isolate and expand [10]. Two different approaches are mainly developed; the first method consists of the bioreactor uses to generate physiological-like stimuli onto cell seeded scaffolds for in vitro TEVG maturation, before the in vivo implantation. The latter approach regards the direct implantation of cell seeded scaffolds in the body that acts as a bioreactor for TEVG maturation. Recently, some studies are focused on the need for off-of-the-shelf grafts for the regeneration of small diameter blood vessels, analyzing the possibility to directly implant acellular scaffolds in the body. The aim of this approach is to develop readily available grafts for urgent vascular surgery.

In the last years increasing interest has been paid to develop an appropriate substitute for small diameter blood vessel replacement. The next paragraphs are focused on the most relevant and recent approaches for vascular tissue regeneration.

2.1. Scaffolds from Decellularized Matrices. Decellularization process aims to remove all cellular and nuclear matter minimizing any adverse effects on the composition, biological activity, and mechanical integrity of the remaining extracellular matrix (ECM) for the development of a new tissue [15-17]. The process usually consists of mechanical shaking, chemical surfactant treatment, and enzymatic digestion [4]. As potential sources of ECM, many organs and tissues (such as skin, ureter, and liver) from humans and animals (such as bovine, sheep, monkeys, pigs, and rabbits) have been decellularized for different applications, such as skin, bone, and valvular heart regeneration $[15,16]$. Decellularized matrix advantages are correlated to its natural three-dimensional ultrastructure and its structural and functional proteins, essential for cell adhesion, migration, proliferation, and differentiation $[10$, 17, 18]. However, the specific composition of the ECM is related to the tissue source. ECM matrices demonstrated to be mainly affected by the age and health status of the animal at harvest and by the manufacturing process, influencing their quality, mechanical and biochemical properties, biocompatibility, and clinical performance [15]. The presence of potential antigenic compound traces (e.g., lipids, DNA, and glycosylation products) may cause an inflammatory response [15, 17]. Furthermore, decellularization procedures may remove desirable ECM components, such as collagen, thus decreasing mechanical properties [15-17]. Decellularized matrices can be stored in hydrated state or in dehydrated lyophilized form. Hydrated ECM matrices demonstrate excellent biomechanical characteristics and improved cellular ingrowth rates; in contrast lyophilized ECM matrices show long shelf life and easy transportability $[15,17]$.

From a historical context, decellularized matrices derived from many animal organs and tissues (such as porcine small intestinal submucosa, porcine aortas) were widely investigated. In 1999, Sullivan's group [19] developed TEVGs made of porcine small intestinal submucosa and type I bovine collagen. Specifically, porcine small intestinal submucosa was chemically decellularized, wrapped around a $4 \mathrm{~mm}$ mandrel, and impregnated with bovine collagen in the TEVG lumen [19]. Then, the collagen layer was crosslinked and coated with heparin-benzalkonium chloride complex [19]. TEVGs were interpositionally implanted in the common carotid artery of rabbits for 90 days [19]. These TEVGs demonstrated excellent patency without hyperplasia and aneurysm formations and allowed the SMC cellularization and the endothelialization, showing physiological vasoreactivity to agonists [19]. In 2000, 
TABLE 1: Compliance of natural vessels and synthetic prostheses.

\begin{tabular}{lccc}
\hline Graft type & Compliance & Elastic modulus & Reference \\
\hline Artery & $5.9 \pm 0.5 \% / 100 \mathrm{mmHg}$ & - & {$[41]$} \\
& $677 \% / \mathrm{MPa}$ & $0.455 \mathrm{MPa}$ & {$[42]$} \\
Saphenous vein & $4.4 \pm 0.8 \% / 100 \mathrm{mmHg}$ & - & {$[41]$} \\
PET & $1.9 \pm 0.3 \% / 100 \mathrm{mmHg}$ & $1.9 \mathrm{MPa}$ & {$[41]$} \\
& $145 \% / \mathrm{MPa}$ & - & {$[42]$} \\
ePTFE & $1.6 \pm 0.2 \% / 100 \mathrm{mmHg}$ & $2.2 \mathrm{MPa}$ & {$[41]$} \\
& $124 \% / \mathrm{MPa}$ & & {$[42]$} \\
\hline
\end{tabular}

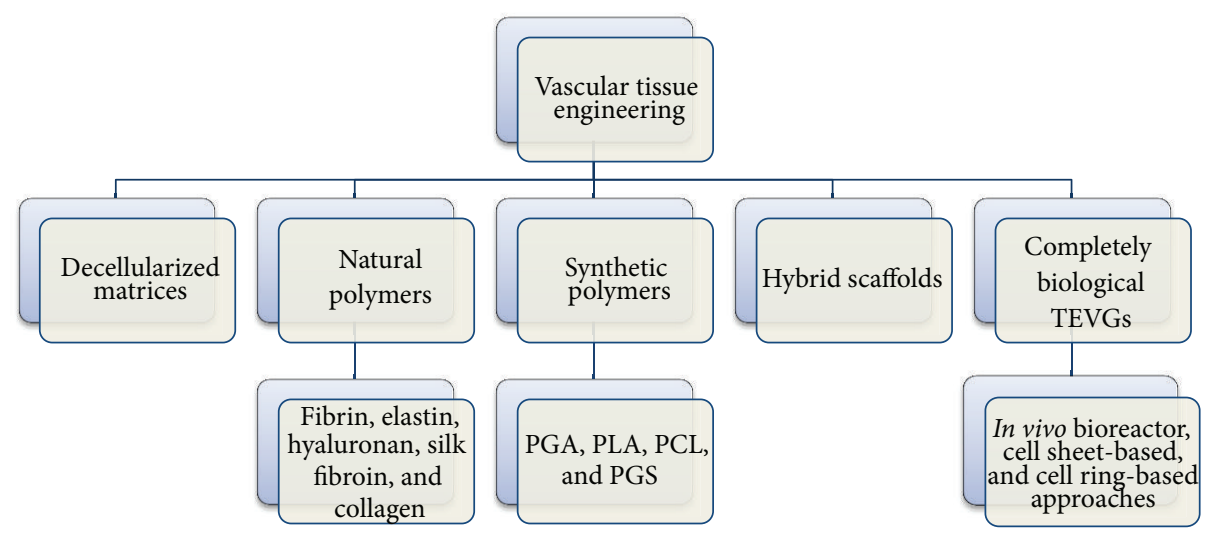

FIGURE 1: Sketch of the review content.

TABLE 2: Requirements of an ideal TEVG, in particular small diameter vessels.

\begin{tabular}{|c|c|}
\hline \multirow{6}{*}{ Biocompatibility } & Nontoxicity \\
\hline & Nonimmunogenicity \\
\hline & Nonthrombogenicity \\
\hline & Nonsusceptibility to infection \\
\hline & Ability to grow for pediatric patients \\
\hline & Maintenance of a functional endothelium \\
\hline \multirow{4}{*}{ Mechanical properties } & Compliance similar to native vessel \\
\hline & Burst pressure similar to native vessel \\
\hline & Kink and compression resistance \\
\hline & Good suture retention \\
\hline \multirow{4}{*}{ Processability } & Low manufacturing costs \\
\hline & $\begin{array}{l}\text { Readily available with a large variety of } \\
\text { lengths and diameters }\end{array}$ \\
\hline & Sterilizable \\
\hline & Easy storage \\
\hline
\end{tabular}

Haverich's group [20] developed a trypsin-based decellularization procedure to remove cells from porcine aortas and, then, a recellularization method using a bioreactor, human peripheral venous ECs, and myofibroblasts. To study the in vivo immune response, decellularized aortas were subcutaneously implanted in the rat model showing a reduced presence of t-lymphocytes and leukocytes in comparison with the control (not decellularized porcine aortas) [20]. They reported for the first time the complete in vitro endothelialization and the in vitro intramural myofibroblast repopulation into decellularized matrices using a bioreactor and human cells [20]. In 2001, Mayer's group [21] chemically decellularized porcine iliac vessels and noninvasively isolated endothelial progenitor cells (EPCs) from peripheral blood of sheep. EPCs were in vitro cultured and rotationally seeded into the decellularized matrices. After 4 days in a laminar flow bioreactor, decellularized vessels were in vivo implanted into the common carotid arteries of sheep by an end-to-end anastomosis [21]. Decellularized vessels remained patent for 130 days due to the presence of EPCs; in fact not seeded decellularized vessels occluded within 15 days [21]. Furthermore, EPCs-decellularized matrices demonstrated contractile activity and nitric oxide mediated vascular relaxation that was similar to native carotid arteries [21]. In 2003, for the first time, Niklason's group [22] developed a decellularization strategy for TEVGs obtained by culturing bovine aortic or porcine carotid SMCs onto polyglycolic acid (PGA) meshes. This approach avoided the use of allogeneic or xenogeneic tissue, eliminating the risk of viral disease transmission due to the possible utilization of highly screened cells [22]. The group improved this approach in the next years as reported in the following (Table 3).

Table 3 reports the most relevant and recent (2008-2013) studies on decellularized matrices for vascular tissue engineering, focusing on the material source, decellularization method, and mechanical and biological performances.

Among all the approaches reported in Table 3, particular attention is paid to an interesting strategy developed by Niklason's group [23] (Figure 2). This approach consisted of a 


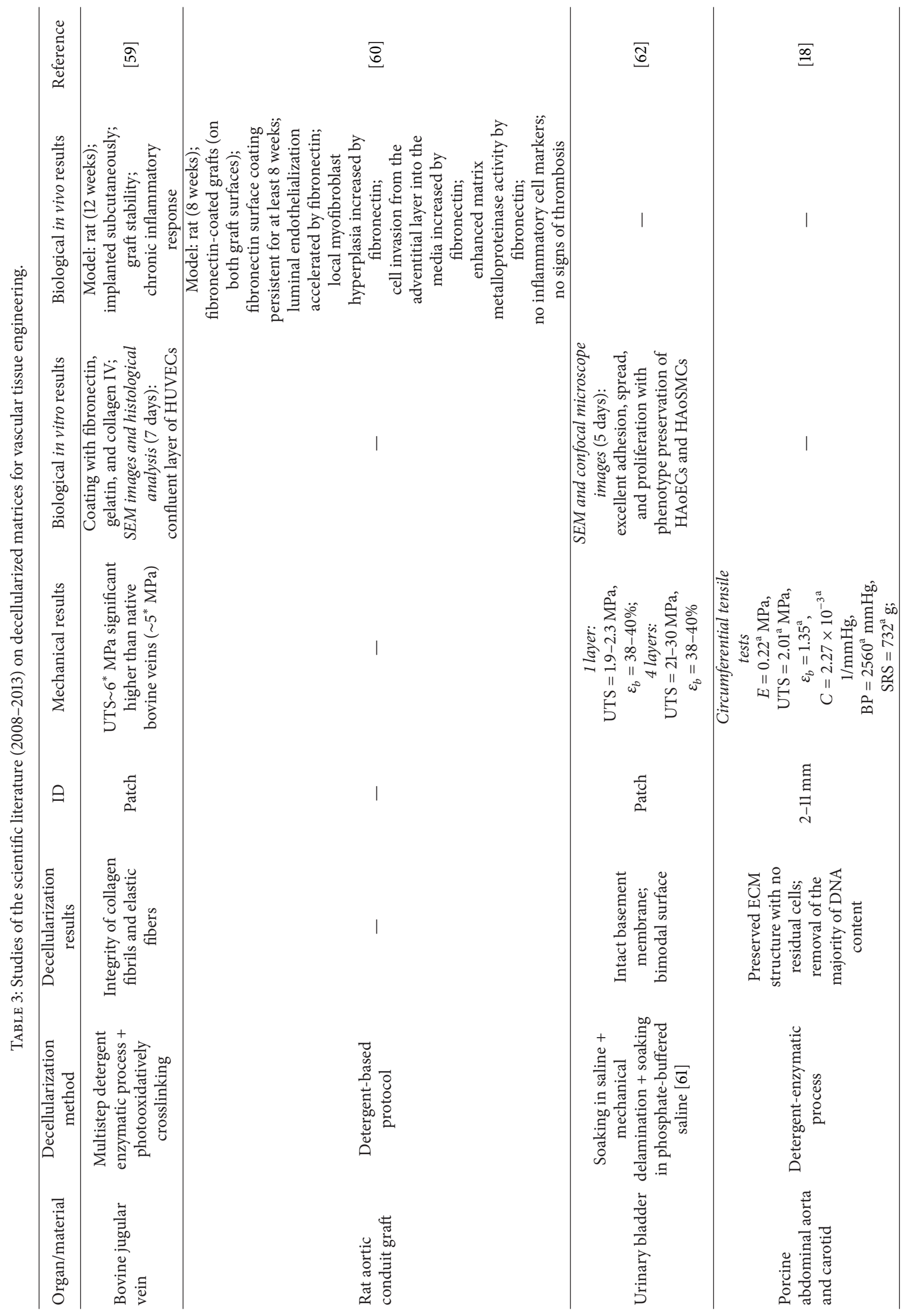




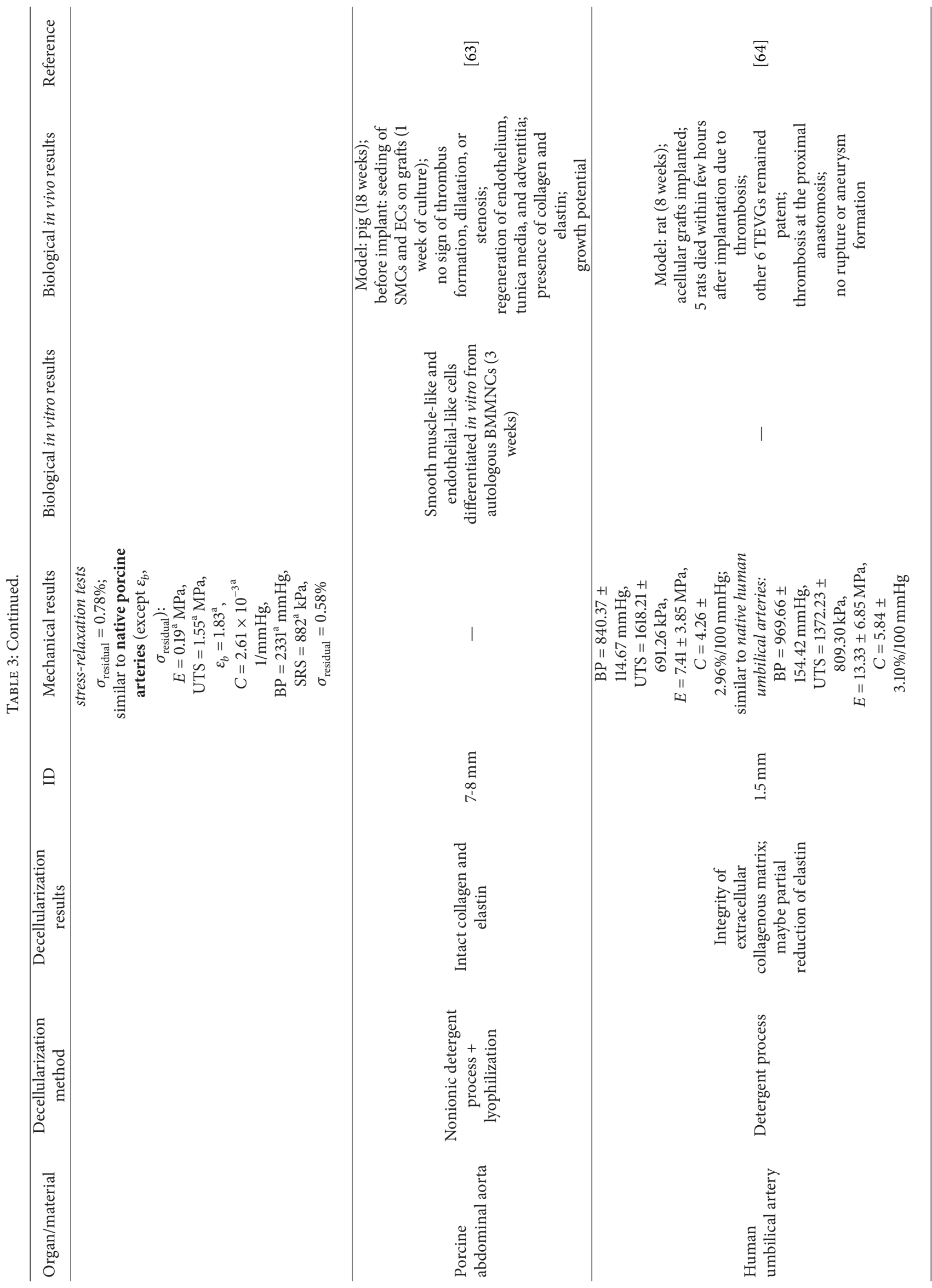




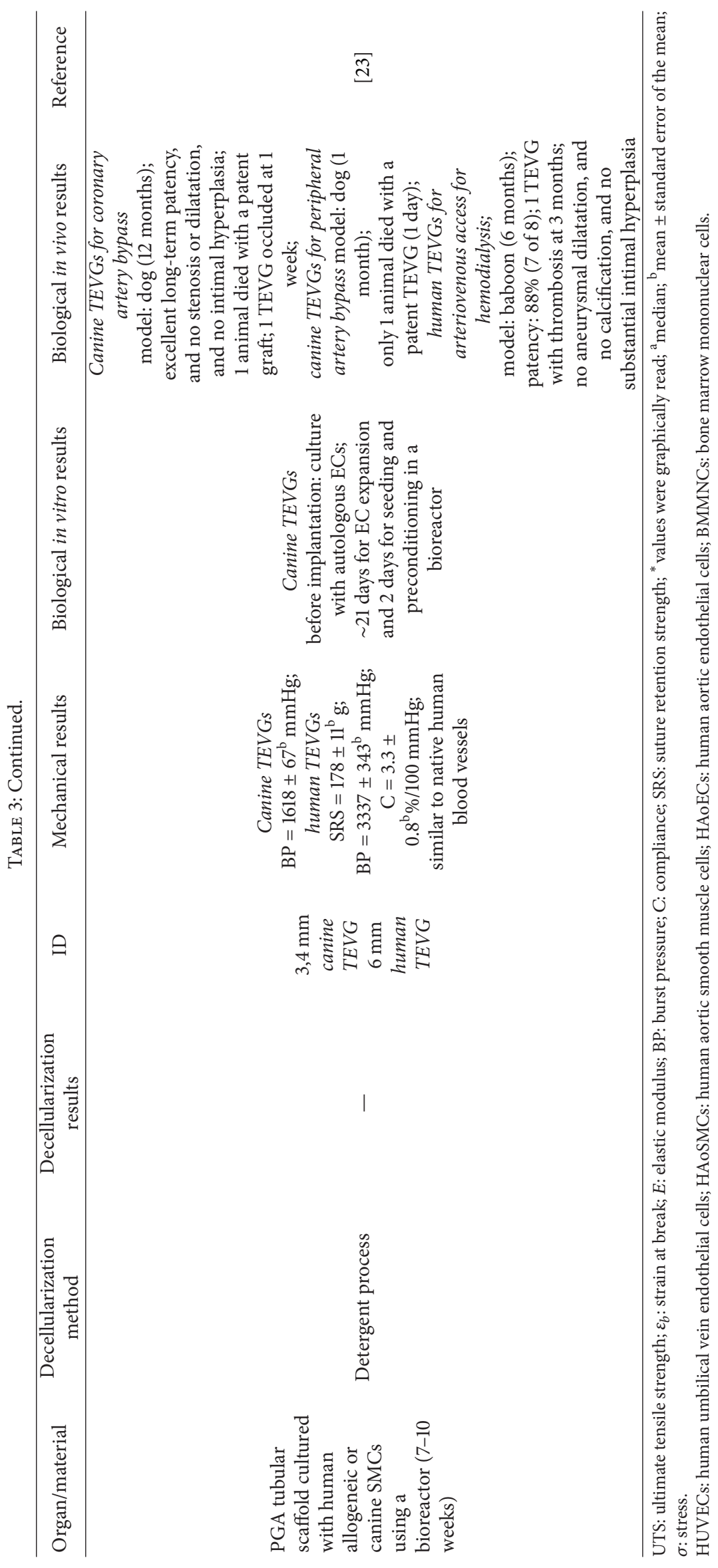


first step for growing allogeneic SMCs onto a PGA tubular scaffold in a bioreactor (Figure 2(a)). The PGA scaffold rapidly degrades, while cells secrete ECM proteins for tissue regeneration (Figure 2(b)). After the maturation period (7-10 weeks), the construct was decellularized and stored in a buffer solution at $4^{\circ} \mathrm{C}$ until the in vivo implantation (Figure 2(c)). TEVGs with ID $\geq 6 \mathrm{~mm}$ were readily available for the implant (Figure 2(d)); in contrast TEVGs with ID $=3-4 \mathrm{~mm}$ were seeded with autologous ECs isolated by a biopsy (Figure 2(e)), before implantation, to provide an antithrombogenic luminal surface, minimizing the risk of graft occlusion [23]. Niklason's group used PGA scaffolds only as a support for the ECM deposition; therefore, the final decellularized constructs did not include the synthetic polymer. This approach may allow the production of many TEVGs using only one human donor [23]. In addition, TEVGs may be produced with the appropriate diameter and ready available due to use of allogeneic cells and decellularization [23].

2.2. Scaffolds from Natural Polymers. Natural polymers generally show excellent biological performances; specifically, they do not activate chronic inflammation or toxicity [24].

Among the natural polymers studied for application in vascular tissue engineering, this paragraph is focused on fibrin, elastin, hyaluronan, silk fibroin, and collagen that show interesting properties for vascular tissue engineering applications and are now the main studied natural polymers.

Fibrin is an insoluble body protein entailed in wound healing and tissue repair $[6,25]$. Fibrin clot, obtained by fibrinogen polymerization due to thrombin, is a fibrillar network gel that provides a structural support for adhesion, proliferation, and migration of cells involved in the healing $[6,25]$. Finally, fibrin clot is resorbed through the fibrinolysis, a fibrinolytic process that breaks down fibrin fibrils $[6,25]$. Fibrinogen may be purified from autologous blood and used for scaffold fabrication avoiding immunological problems $[6,25]$.

Elastin is one of the major ECM proteins in the arterial wall $[6,25-27]$ that confers elastic recoil, resilience, and durability [26-28]. It is an important autocrine regulator to SMC and EC activity, inhibiting migration and proliferation of SMCs and enhancing attachment and proliferation of ECs $[26,28]$. Elastin, as a coating of vascular devices (made of ePTFE [29], PET, a copolymer of ePTFE and polyethylene, and a polycarbonate polyurethane [30]), demonstrated low thrombogenicity with reduced platelet adhesion and activation $[26,27]$.

Hyaluronan is an anionic nonsulfated glycosaminoglycan (GAG) that consists of glucuronic acid and $\mathrm{N}$-acetyl glucosamine [6]. It can be produced in large amount by microbial fermentation [25]. Furthermore, hyaluronic acid is hydrophilic, nonadhesive, biocompatible, and biodegradable $[6,25]$.

Silk fibroin is a protein produced by silkworms and spiders [31]. The amino acid structure of silk fibroin from Bombyx mori is composed mainly of glycine (43\%), alanine $(30 \%)$, and serine (12\%) [31]. It shows excellent mechanical properties and biocompatibility [31]. Silk degrades slowly and

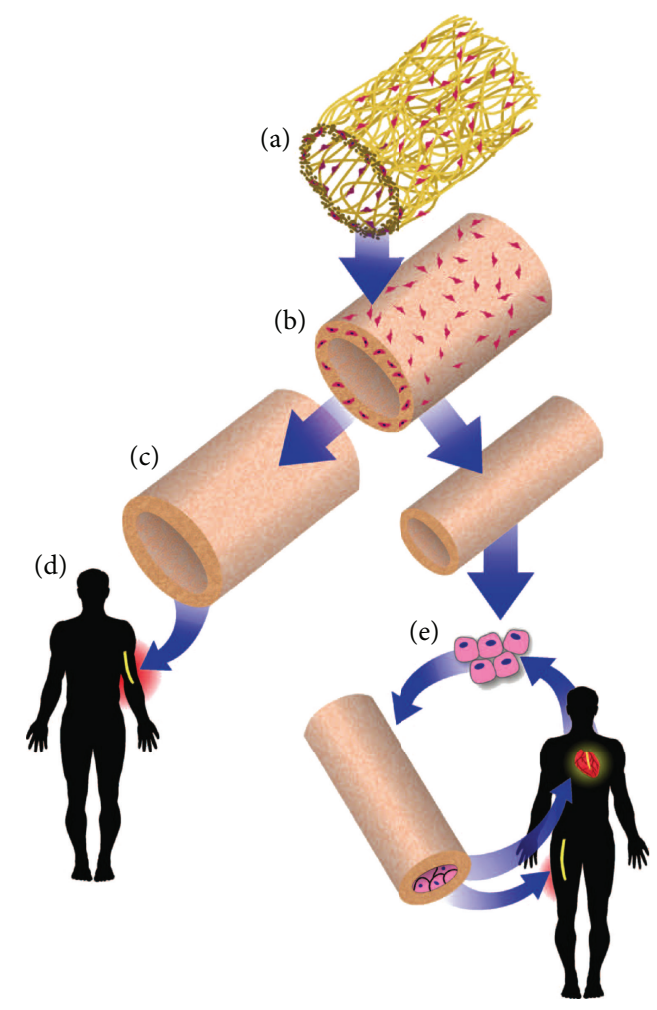

FIGURE 2: Sketch of the innovative strategy developed by Niklason's group, from [23] (reprinted with permission from AAAS).

proteolytically in vivo, maintaining more than $50 \%$ of its mechanical properties after 2 months [32].

Collagen is the major ECM protein in the body that supplies mechanical support to many tissues [6]. Collagen demonstrates low antigenicity, low inflammatory response, biocompatibility, biodegradability, and excellent biological properties $[6,25,33]$. Collagen type $I$ is one of the main components of the vascular wall, whereas it is widely used as scaffold for vascular tissue engineering applications [6].

Seminal studies on the use of natural polymers for TEVG are concerned with the development of scaffolds made of collagen or fibrin. In 1986, Weinberg and Bell reported the design and the fabrication of the first TEVG made of collagen gel and cells [34]. Specifically, they developed a tubular graft by casting and gelling bovine aortic SMCs and collagen in an annular mold at $37^{\circ} \mathrm{C}$, to mimic the tunica media [34]. Then, a mixture of collagen and bovine aortic adventitial fibroblasts was cast around the first tube to recreate the tunica adventitia and, finally, bovine aortic ECs were seeded into the lumen [34]. Unfortunately, the burst pressure of the obtained TEVG was very low and less than $10 \mathrm{mmHg}$ [34]. Therefore, a PET mesh was added allowing for an increase of the burst pressure $(40-70 \mathrm{mmHg})$ [34]. Furthermore, a TEVG composed of three layers of collagen gel and two PET meshes reached a burst strength of $120-180 \mathrm{mmHg}$ [34]. In 2000, Nerem's group [35] designed a dynamic mechanical conditioning method to improve the mechanical properties of adult rat aortic SMCs entrapped in a collagen-gel scaffold. The TEVG was cultured onto an inflatable silicone tube allowing for the transmission of the mechanical stimuli (i.e., 
cyclic strain) [35]. Due to the mechanical conditioning, SMCs increased their circumferential orientation, leading to an improvement of mechanical properties (higher yield stress, ultimate stress, and elastic modulus) [35]. In 2002, Tranquillo's group [36] demonstrated that neonatal aortic rat SMCs embedded in fibrin gel were stimulated to increase the collagen production in comparison with SMCs entrapped in collagen gel. Furthermore, they inhibited the rapid fibrin degradation by SMCs, due to the addition of $\varepsilon$-aminocaproic acid to the culture medium that avoids the binding of plasmin or plasminogen to fibrin [36]. After 6 weeks of in vitro incubation in TGF- $\beta$ and insulin, tubular fibrin gel with entrapped SMCs exhibited ultimate tensile strength and elastic modulus similar to those of rat abdominal aorta [37]. In 2005, Andreadis's group [38] developed scaffolds based on ovine SMCs embedded in fibrin gels, using aprotinin as fibrinolysis inhibitor. After 2 weeks in culture, ovine ECs were seeded on the outer surface of the TEVG and cultured for 3 or 10 days [38]. After the reversion of TEVGs (i.e., ECs in the TEVG lumen), TEVGs were interpositionally in vivo implanted in jugular veins of 12 -week-old lambs for 15 weeks [38]. TEVGs remained patent and showed blood flow rates similar to those of the native jugular vein [38]. Furthermore, TEVGs allowed the production of elastin and collagen fibers, the SMC circumferential alignment, and the presence of a uniform endothelium [38].

In the last years (2008-2013, Table 4), many research groups studied the possible use of natural polymers for TEVGs, following the first results previously obtained [3438].

Among the number of recent studies developed to fabricate TEVGs using natural polymers, particular attention is paid to structural proteins, such as fibrin $[39,40]$, elastin [27], and collagen [33], and to the methods to improve their mechanical properties $[39,40]$ (Table 4). Simultaneously, silk fibroin is widely investigated for vascular application due to its higher mechanical properties in comparison to other natural polymers, such as fibrin [39] (Table 4). However, it is difficult to compare mechanical properties among different studies because of the different conditions used for mechanical characterization, such as crosshead speed, sample shape (rectangular, tubular), and applied load direction.

\subsection{Scaffolds from Biodegradable Synthetic Polymers. Biodeg-} radable synthetic polymers generally demonstrate tailorable mechanical properties and high reproducibility and, compared to natural polymers, can be produced in large amounts $[27,43]$.

Among the biodegradable synthetic polymers under study for application in vascular tissue engineering, this paragraph is focused on polyglycolic acid (PGA), polylactic acid (PLA), poly- $\varepsilon$-caprolactone (PCL), and polyglycerolsebacate (PGS).

$P G A$ is a semicrystalline, thermoplastic aliphatic polyester synthesized by the ring-opening polymerization of glycolide $[6,25]$. It degrades rapidly in vivo by hydrolysis to glycolic acid, metabolized and eliminated as carbon dioxide and water, and completely degrades in vivo within 6 months [6]. PGA is a Food and Drug Administration (FDA) approved polymer [10] for human clinical use.
$P L A$ is a thermoplastic aliphatic polyester synthesized by ring-opening polymerization of lactic acid $[6,25]$. It demonstrates good biocompatibility and mechanical properties and the ability to be dissolved in common solvents for processing [44]. PLA is more hydrophobic than PGA, leading to a slower degradation rate $[6,25]$. It is a FDA approved polymer [10] for human clinical use. PLA is a chiral molecule: poly-D-lactide (PDLA) and poly-L-lactide (PLLA) are the enantiomeric semicrystalline forms; in contrast the racemate, poly-D,Llactide (PLA), presents an amorphous structure $[6,44]$. PLLA takes months or even years to lose its mechanical integrity [25].

$P C L$ is a semicrystalline, aliphatic polyester synthesized by the ring-opening polymerization of $\varepsilon$-caprolactone $[6,25$, 45]. It shows good mechanical properties, specifically high elongation and strength, and good biocompatibility $[45,46]$. Furthermore, PCL degrades very slowly in vivo by enzymatic action and by hydrolysis to caproic acid and its oligomers $[6,45]$. It takes more than 1 year to completely degrade in vivo $[45,46]$. PCL is a FDA approved polymer [6].

$P G S$ is an elastomer synthesized by polycondensation of glycerol and sebacic acid [47]. It demonstrates good biocompatibility and good mechanical properties, specifically high elongation and low modulus, indicating an elastomeric and tough behavior [47]. PGS degrades in vivo by hydrolysis in 2 months [47]. The FDA approved glycerol and polymers containing sebacic acid for medical applications [47].

Seminal studies are mainly concerned with the development of scaffolds made of PGA. In 1997, Langer's group [49] designed PGA mesh tubular scaffolds coated with PLLA or 50/50 PLGA copolymer to stabilize PGA meshes. TEVGs were implanted into the omentum of rats demonstrating the in vivo maintenance of their structure. Furthermore, TEVGs were in vitro seeded and cultured with bovine aortic SMCs and ECs, demonstrating good adhesion and cell proliferation up to 14 days. In 1999, they developed PGA scaffolds chemically modified with sodium hydroxide to increase hydrophilicity [50]. Bovine aortic SMCs were in vitro seeded and cultured onto PGA scaffolds under pulsatile radial stress using a bioreactor [50]. After 8 weeks, SMCs migrated in the TEVG wall thickness and bovine aortic ECs were seeded and cultured into the TEVG lumen under continuous perfusion [50]. The TEVG demonstrated good mechanical strength [50]. TEVG was interpositionally implanted into the right saphenous artery of miniature swine and remained patent for 4 weeks, even though there was a decrease of the blood flow [50]. Furthermore, histological analysis showed highly organized structure with minimal inflammation [50]. In 1999, Mayer's group [51] designed scaffolds made of a copolymer of PGA and polyhydroxyalkanoate (PHA). Specifically, ovine carotid arteries were harvested and cultured in vitro [51]. After 6-8 weeks, autologous mixed cell population of ECs, SMCs, and fibroblasts was seeded and cultured onto TEVGs [51]. Then, TEVGs were implanted in the abdominal aortas of lambs for 5 months [51]. All TEVGs remained patent without aneurysm formations and histological analysis showed the presence of elastic fibers in the tunica media and ECs in the tunica intima [51]. During the implantation period, the TEVG mechanical properties changed and became similar 


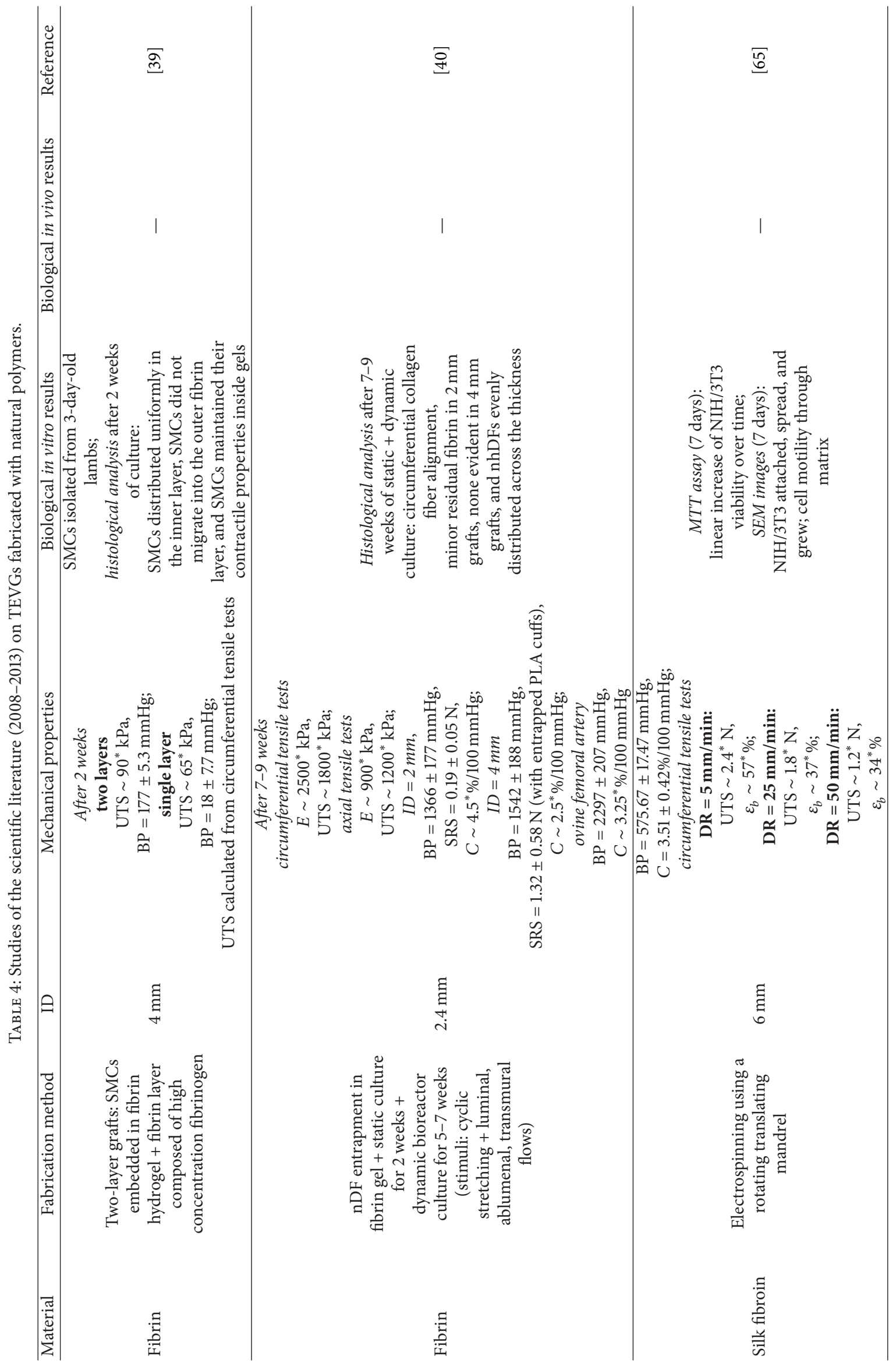




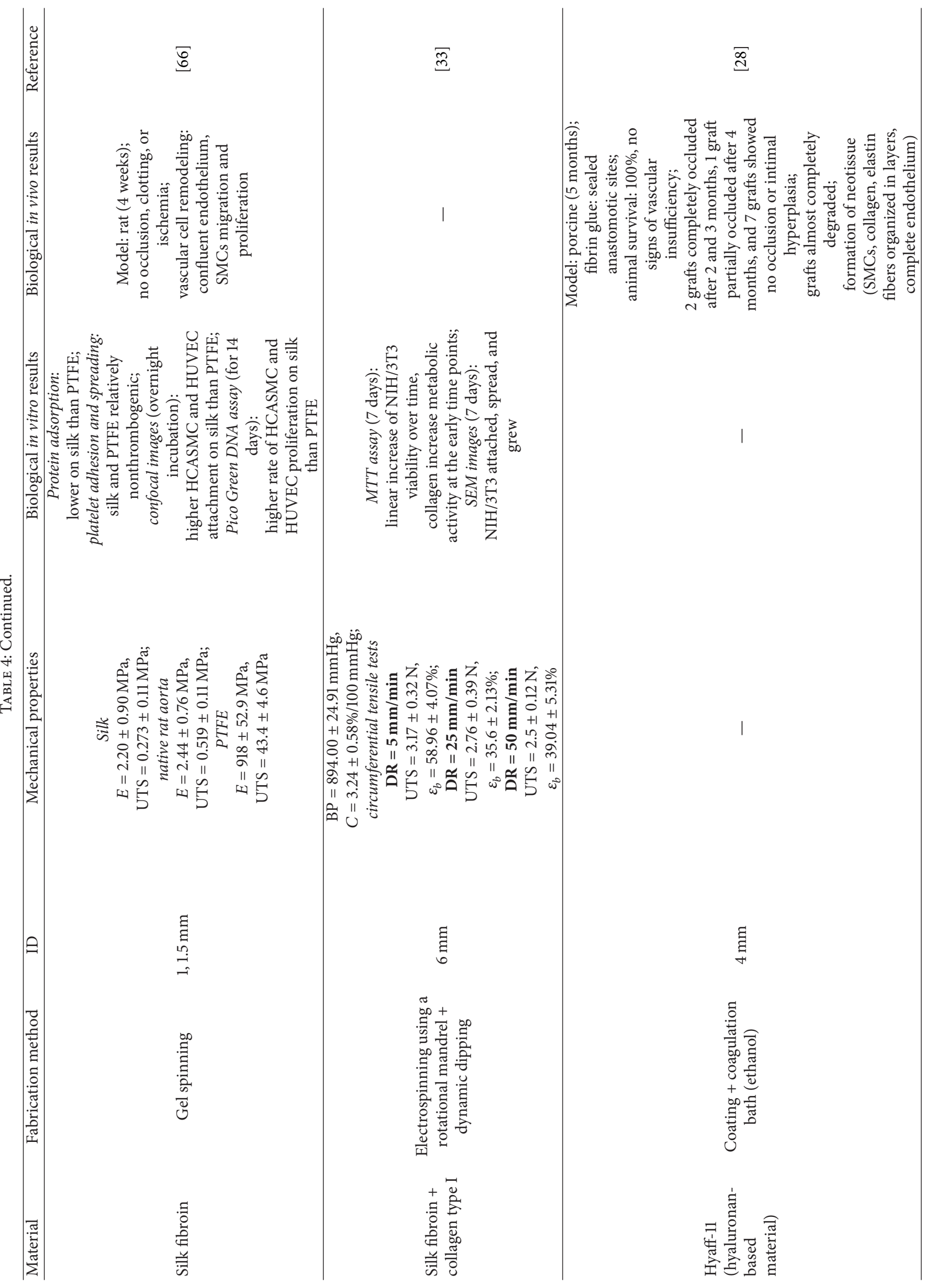




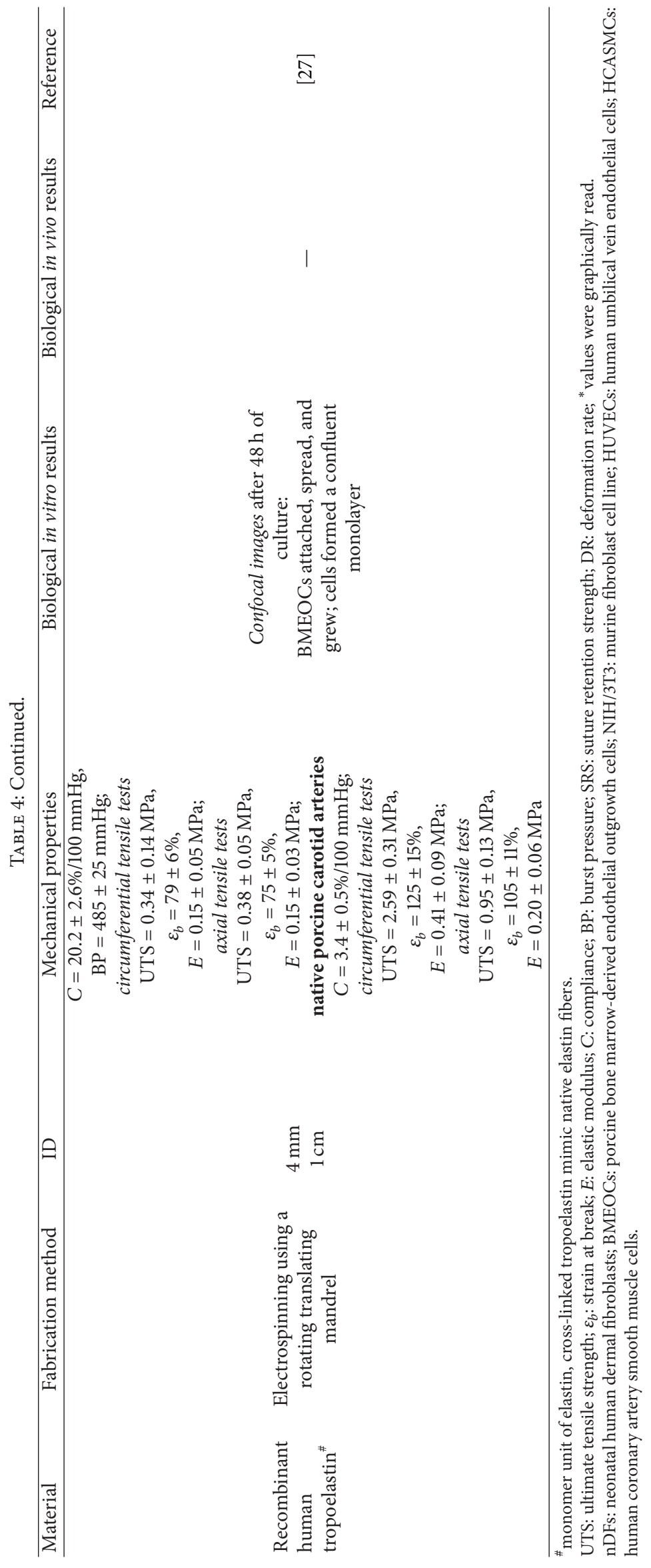


to those of native vessels [51]. In 2001, Shinoka's group [52] performed the first transplantation of a TEVG in four-yearold girl. The TEVG consisted of PGA mesh coated with a $50: 50$ copolymer of L-lactide and $\varepsilon$-caprolactone, previously in vitro seeded with autologous vascular cells isolated from peripheral vein biopsies [52]. After 7 months, there was no evidence of aneurysm or stenosis formations [52]. The clinical trial performed by Shinoka's group is widely described in Section 4.

Among the several recent studies (2008-2013, Table 5) developed to fabricate TEVGs using biodegradable synthetic polymers, particular attention is paid to PCL due to its deformability and mechanical strength (Table 5). PCL was studied alone $[46,53,54]$, as multilayers (PGA-PCL-PGA [55]), electrospun coating on PGS [56], or copolymer with L-lactide [57, 58] (Table 5). For example, the use of PCL as PGS tube coating increased the mechanical properties of the substrate, specifically suture retention strength, elastic modulus, and ultimate strength stress [56].

2.4. Synthetic versus Natural Scaffolds. TEVGs should have appropriate biological behavior and mechanical properties to reach the clinical use. TEVG biological performance should support the complete integration of the grafts in the human body, avoiding the induction of a chronic inflammatory response during the material degradation process. Furthermore, TEVG mechanical properties should match those of the native blood vessels, specifically in terms of deformability, compliance, and strength.

One of the essential principles of tissue engineering is the choice of a scaffold with appropriate degradation rate during the in vivo remodeling process. The speed of the scaffold degradation has to match the tissue-dependent regeneration rate to develop a functional substitute. For vascular tissue engineering, the key point is the maintenance of the structural and mechanical integrity of the neovascular tissue over all the regeneration process.

Generally, natural polymers lack mechanical performance, but they exhibit excellent biological behavior. As reported in Table 4, tropoelastin electrospun scaffolds showed low mechanical strength compared to native blood vessels, specifically, in terms of ultimate tensile strength $(0.34 \pm 0.14 \mathrm{MPa})$ and burst pressure $(485 \pm 25 \mathrm{mmHg})$ [27]. However, in vitro cell culture demonstrated a good interaction with porcine bone marrow-derived endothelial outgrowth cells, forming a confluent monolayer after 2 days [27].

Normally, natural scaffolds are seeded and cultured in vitro with cells prior to in vivo implantation to obtain a partial remodeling of the structure due to ECM deposition. This in vitro remodeling usually leads to an increase of the graft mechanical properties. As reported in Table 4, fibrin gels with entrapped SMCs were dynamically cultured in a bioreactor for several weeks to achieve a circumferential alignment similar to native arteries [40]. This alignment improved the mechanical properties of the grafts, reaching values similar to native blood vessels [40]. To date, studies related to natural materials for vascular applications are focused on the improvement of graft mechanical properties. To reach this goal, some approaches consist of tissue in vitro maturation [40]. Other methods combine the use of natural materials with synthetic polymers (such as tropoelastin with PCL [26]), reaching sometimes promising results in terms of mechanical properties and cell/material interaction.

Synthetic polymers show controllable physical and mechanical properties but lack in biological performances. The products of PGA degradation could lead to a SMC dedifferentiation and to a $\mathrm{pH}$ decrease, potentially inducing an undesired inflammatory response $[10,39,68]$. For example, as reported in Table 5, PCL electrospun scaffolds demonstrated high elongation, similar to that of native arteries, and slow degradation, allowing for cell infiltration and tissue regeneration $[46,53,54]$. A long-term in vivo study of the PCL electrospun tubes was performed in the rat aorta for 18 months [46]. During the first 6 months, PCL electrospun scaffolds induced a promising tissue regeneration with a rapid colonization and a wide neovascularization [46]. In fact, fibroblasts and macrophages infiltrated and proliferated in the PCL graft mainly from the adventitial side; the fibroblasts become myofibroblasts that deposed a natural ECM in the PCL graft wall and the macrophages secreted angiogenic factors to induce neovascularization [46]. After 6 months, tissue regeneration showed a clear regression with a reduction of capillaries and fibroblasts, an increase of calcification, and a cell regression in intimal hyperplasia [46]. The tissue regression was caused by macrophage disappearance, inducing the neovascularization decrease and the consequent myofibroblast reduction, due to the decrease of oxygen and nutrient presence [46]. Furthermore, calcifications were related to the process of chondroid metaplasia that initially regards the transdifferentiation of smooth muscle cells into chondrocytes in the intimal hyperplasia layers [46]. Therefore, PCL electrospun tubes developed by de Valence et al. [46] demonstrated insufficient regeneration of the blood vessels on the long term (18 months); this result was unexpected because of the promising conclusions obtained in a previous study [79] regarding the implantation of PCL electrospun graft in rat model for 6 months. Specifically, the PCL electrospun grafts demonstrated patency, structural integrity, faster endothelialization, ECM formation, and fiber degradation during 6 months [79].

\subsection{Hybrid Scaffolds from Synthetic and Natural Polymers.} Recent studies have proposed hybrid scaffolds, made of synthetic and natural polymers, to combine the adequate mechanical properties of synthetic materials with the excellent biological behavior of natural polymers.

Table 6 reports the most relevant and recent (2008-2013) studies on TEVGs fabricated using hybrid scaffolds made of natural and biodegradable synthetic materials, focusing on the fabrication method and mechanical and biological performances.

Among the several recent studies aimed to fabricate TEVGs using hybrid scaffolds, particular attention is paid to the use of PCL with natural polymers such as elastin $[26,68]$ and collagen $[45,68,70]$ (Table 6). As an example, the addition of PCL to tropoelastin electrospun scaffolds improved 


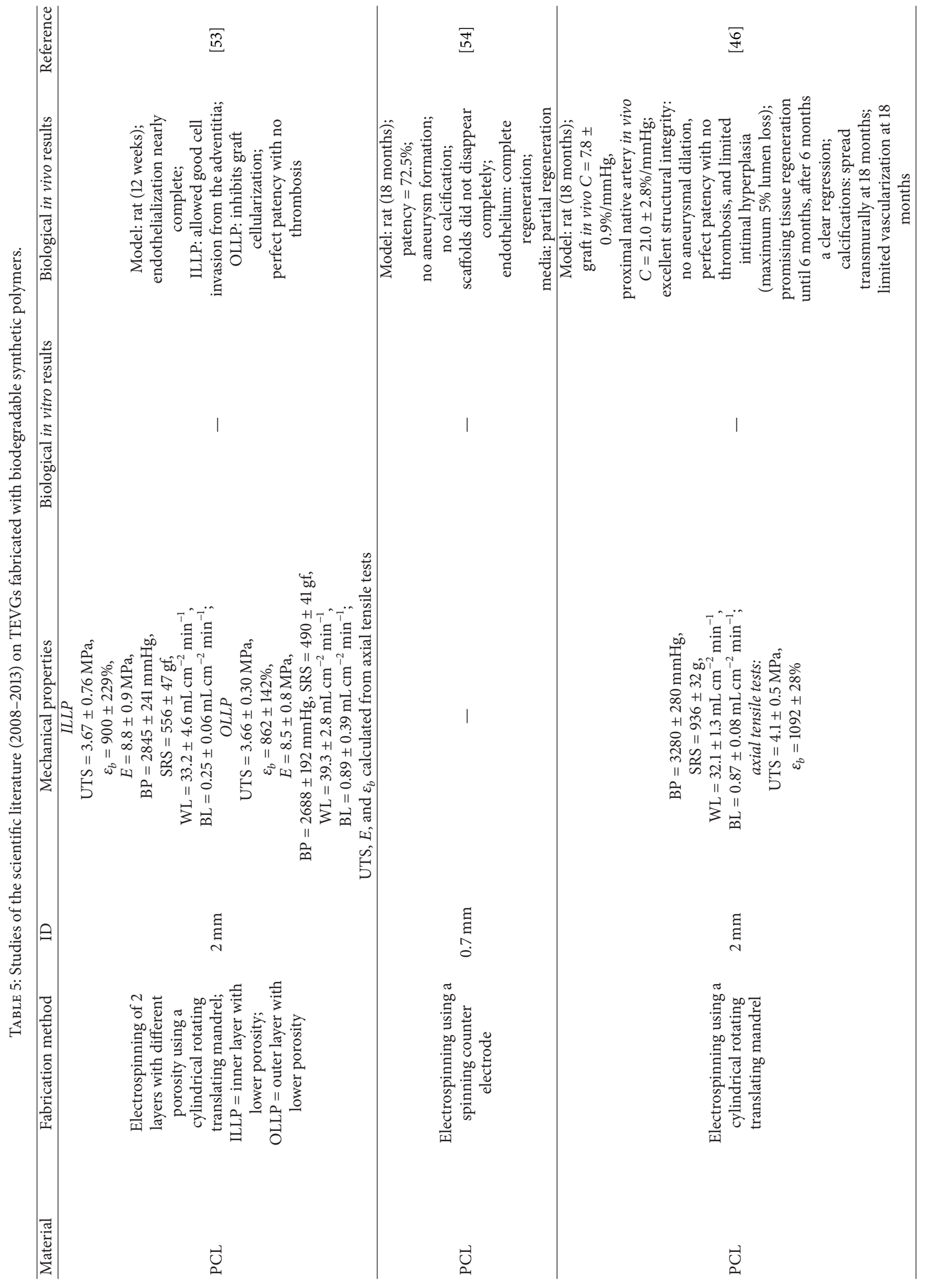




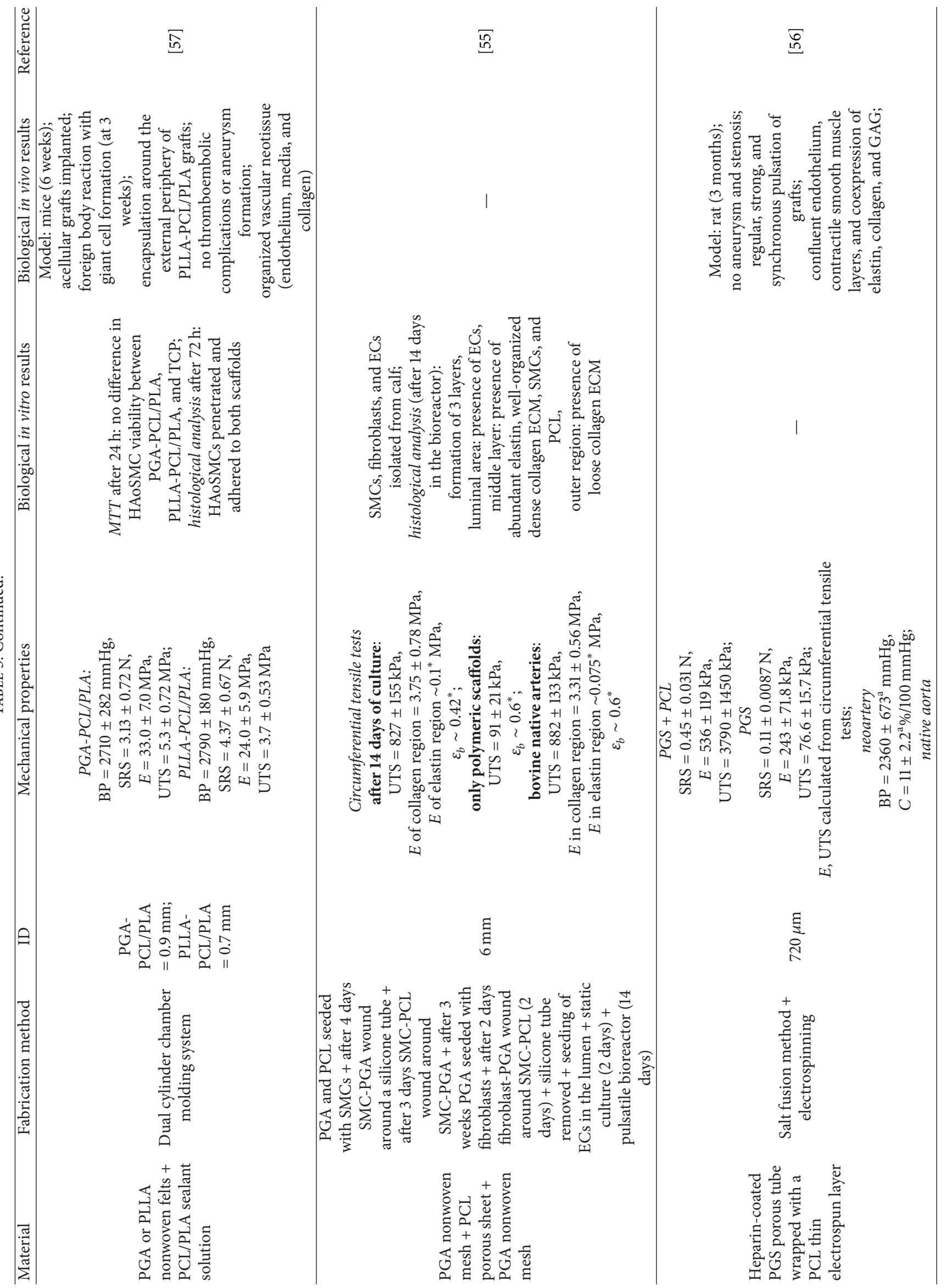




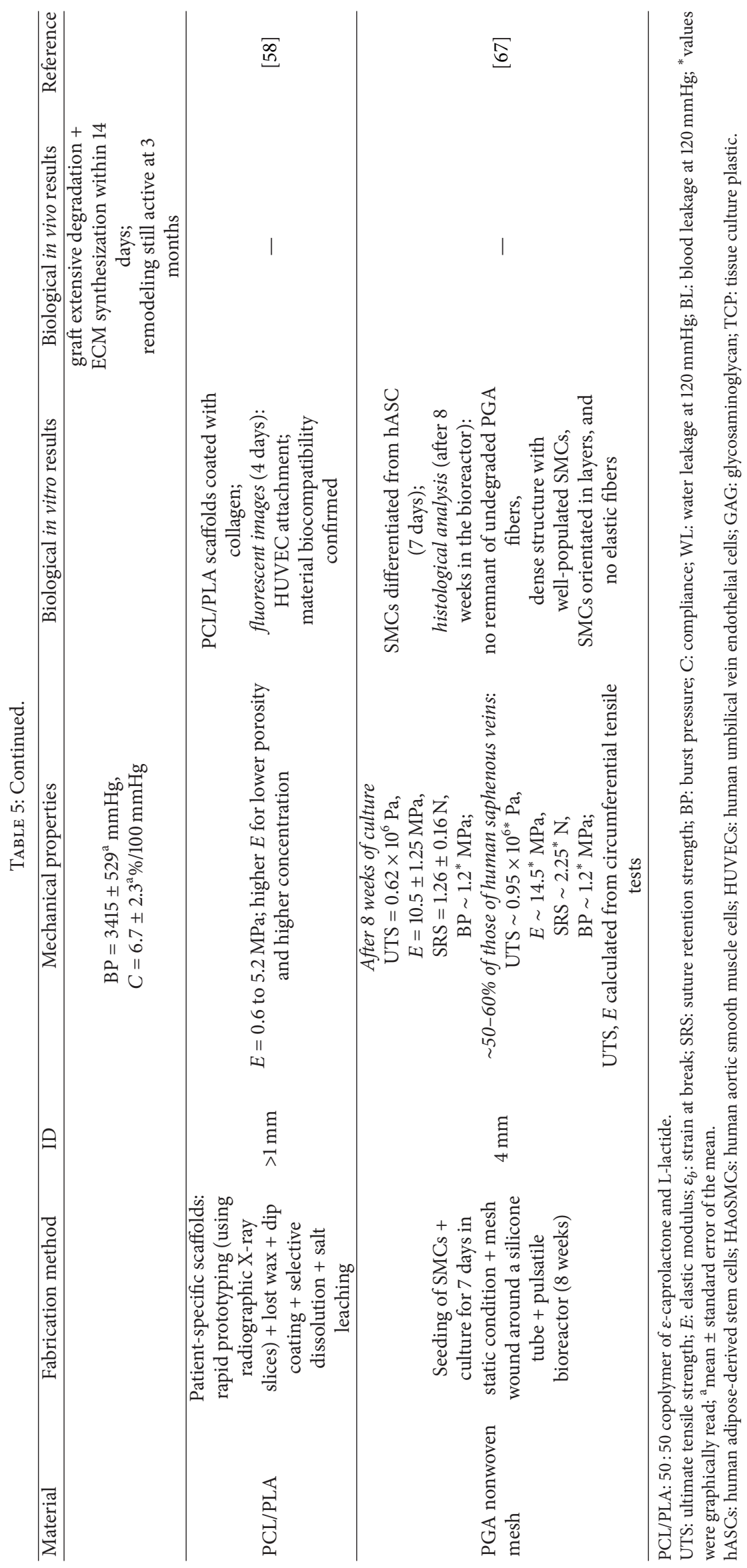




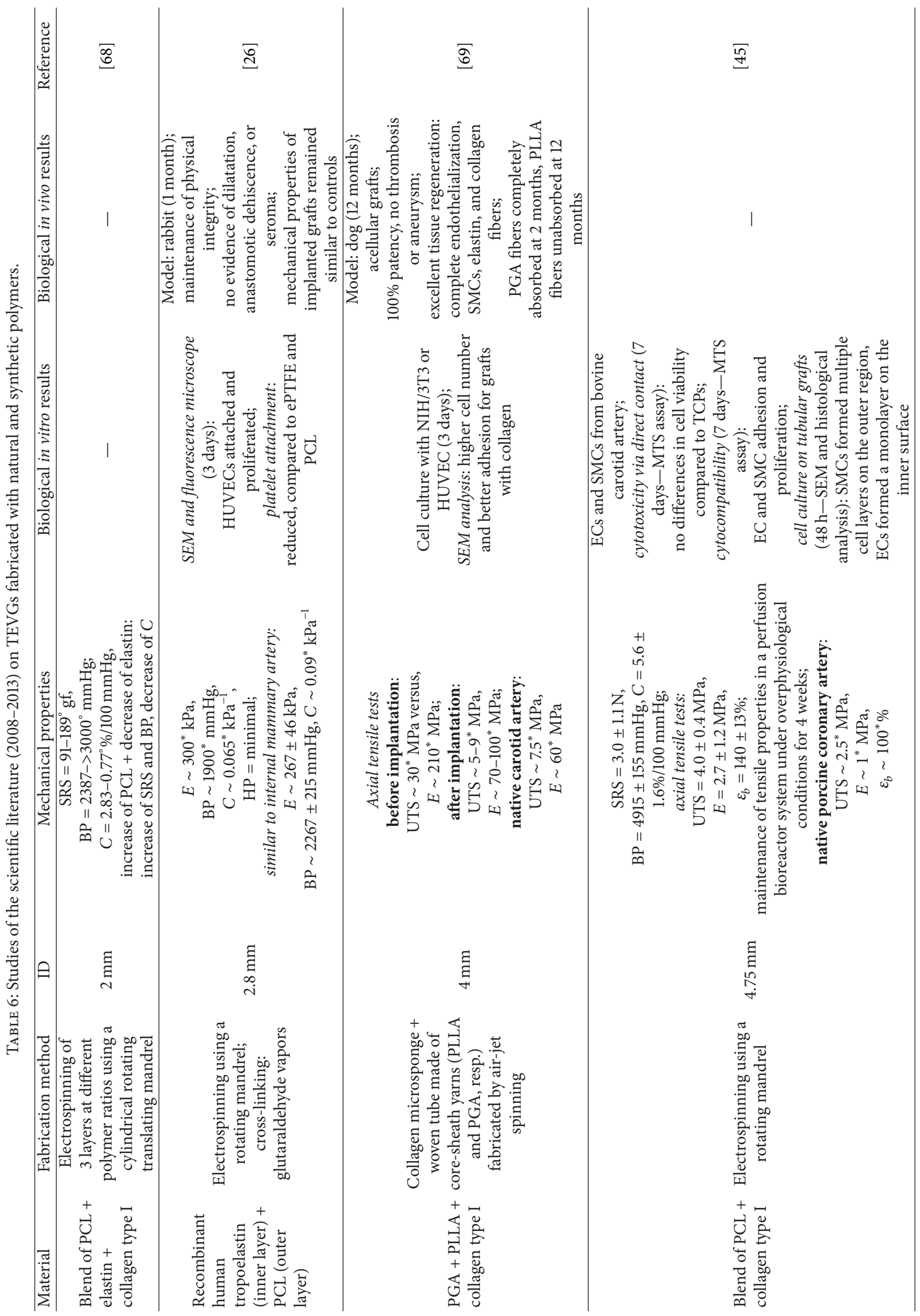




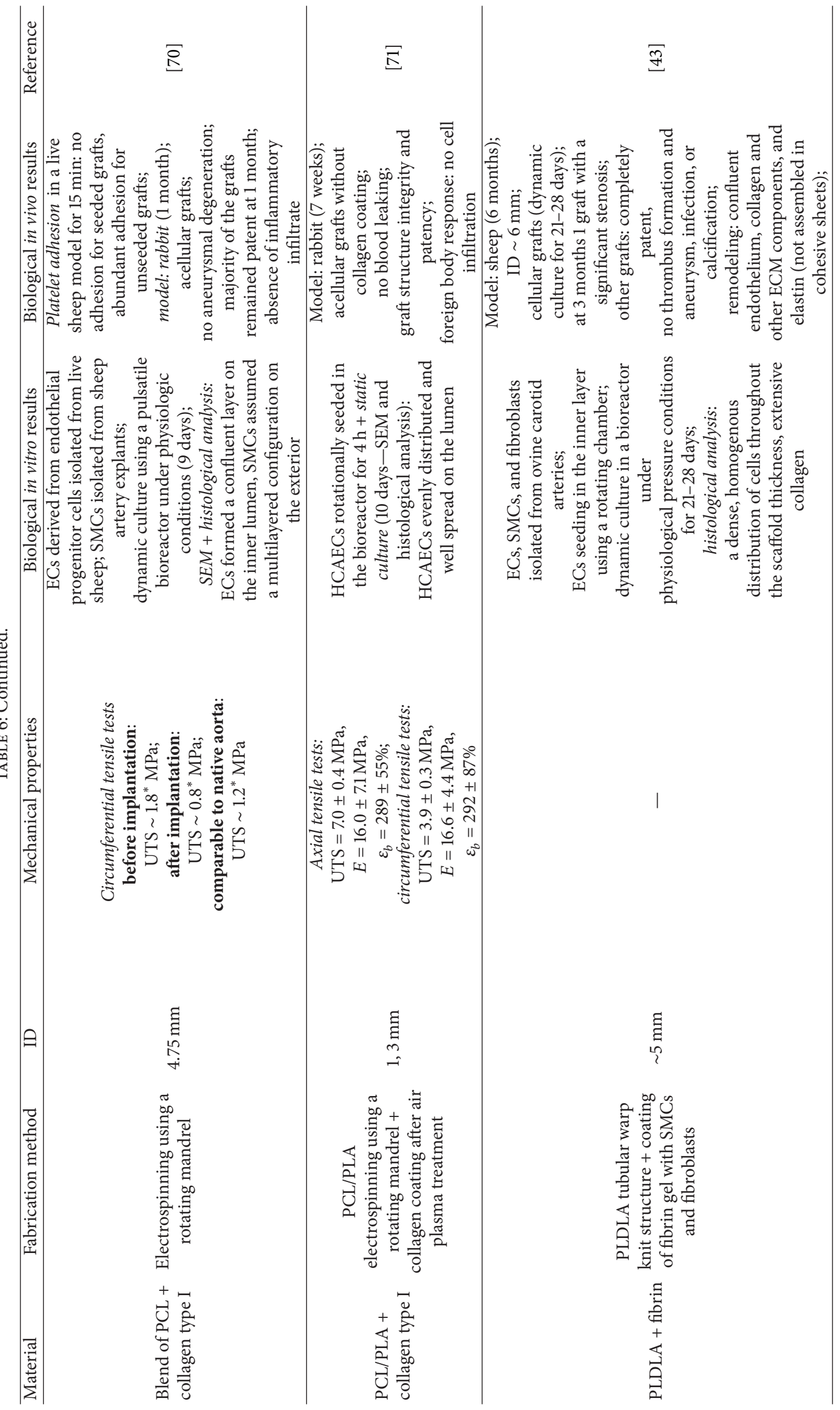




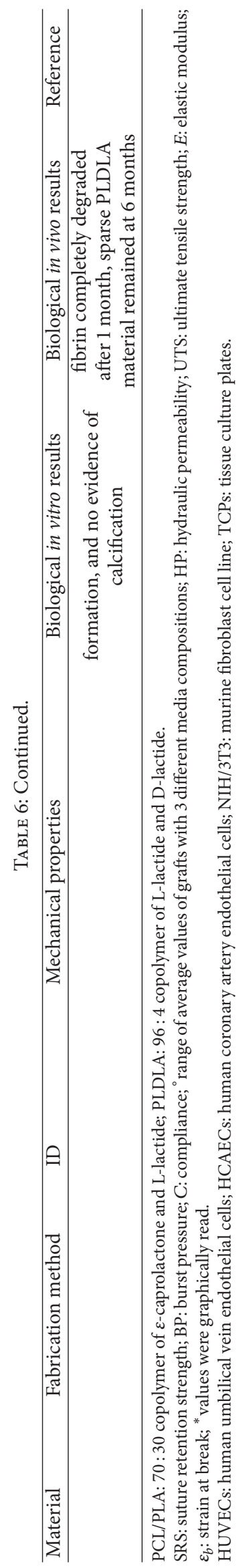




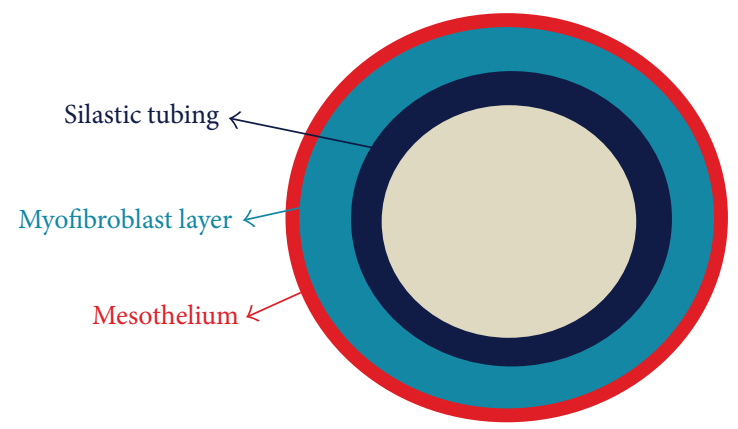

(a)

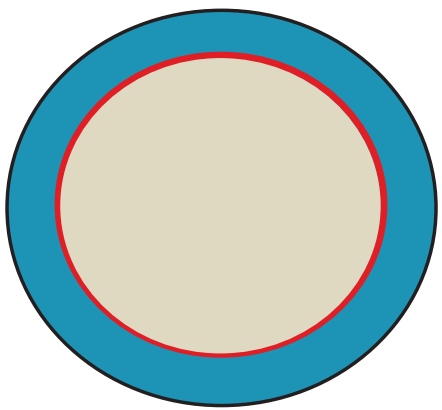

(b)

Figure 3: Sketch of the in vivo bioreactor approach; (a) fibrous capsule formed around a Silastic tubing in the peritoneal cavity; (b) after removal of Silastic tubing, reversion of fibrous capsule, the mesothelium was the inner layer.

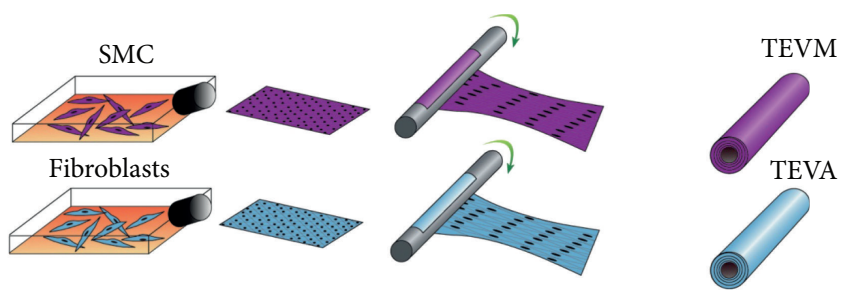

(a)

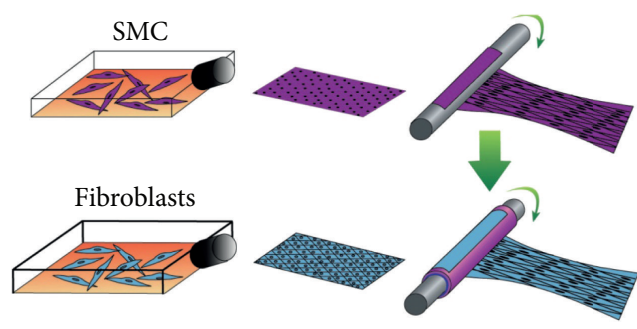

(b)

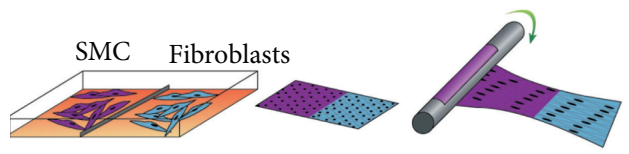

(c)

FIGURE 4: Sketch of different cell sheet-based approaches; (a) tissueengineered vascular media (TEVM) and tissue-engineered vascular adventitia (TEVA) were assembled by rolling a single cell sheet of SMCs or fibroblasts; (b) the standard approach, to produce a TEVMA, required rolling a fibroblast sheet around a SMC sheet (stdTEVMA); (c) the single-step TEVMA was produced due to the presence of SMCs and fibroblasts in the same sheet (ssTEVMA), from [48]. The publisher for this copyrighted material is Mary Ann Liebert, Inc. publishers.

the mechanical properties, making them more similar to native blood vessels [26, 27] (Tables 4 and 6). Specifically, compliance and burst pressure of PCL/tropoelastin scaffolds decreased and increased, respectively, when compared to scaffolds made of tropoelastin alone [26, 27] (Tables 4 and $6)$.
2.6. TEVGs without Scaffolds. Some studies were focused on fabrication of completely biological TEVGs without the use of scaffolds. This strategy avoids problems that may be related to synthetic materials, such as inflammation, stenosis, and infection, allowing for the complete graft integration and increase of the patency rate $[8,25]$. Three main approaches have been developed: the in vivo bioreactor, the cell sheetbased, and the cell ring-based methods.

The in vivo bioreactor approach consists in the use of the body as a bioreactor, as a consequence of the foreign body reaction due to the implantation of a "nonself" material [6]. A Silastic (silicone compound) tubing was implanted in the autologous peritoneal cavity inducing a foreign body reaction with the formation of a fibrous capsule around the mandrel $[8,25,80]$. The fibrous capsule was composed of myofibroblasts, collagen matrix, and a single layer of mesothelial cells (Figure 3(a)) $[8,25,80]$. After 2-3 weeks, the explanted tube of tissue was removed from the Silastic mandrel and reversed, so the mesothelium represented the inner layer (Figure 3(b)) [25]. The main limitations of this method are the requirement of a double surgery and the possible TEVG adhesion to the peritoneal wall during maturation $[8,80]$ and, hence, the damage to the mesothelium (the external layer).

The cell sheet-based approach consists of the in vitro growing of cells in the presence of ascorbic acid in the culture medium to generate a large production of ECM [8]. After a maturation period, cell sheets were detached from the culture flasks and rolled onto a mandrel (Figure 4) [8]. TEVGs were cultured for about 8 weeks until the layers merged in a uniform structure (Figure 4) [8]. The major limitation of this approach is the long time required for the in vitro TEVG growth prior to implantation (6 to 9 months [81]).

The cell ring-based approach consists of the preparation of TEVGs from aggregated cells and cell-derived ECM, due to the use of annular agarose wells [73]. Immortalized rat aortic smooth muscle cells seeded into annular agarose wells with different ID $(2,4$, or $6 \mathrm{~mm})$ aggregated and formed thick tissue rings within 2 weeks of in vitro static culture (Figure 5) [73]. Tissue rings could be fused to generate tubular constructs. Specifically, tissue rings were placed onto silicone tube mandrels and cultured in close contact for 7 days to prepare cohesive tubular constructs [73]. 


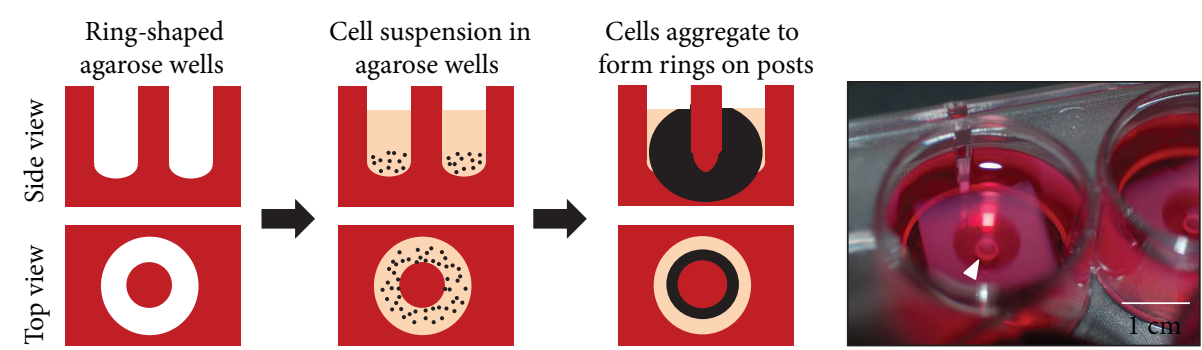

(a)

(b)

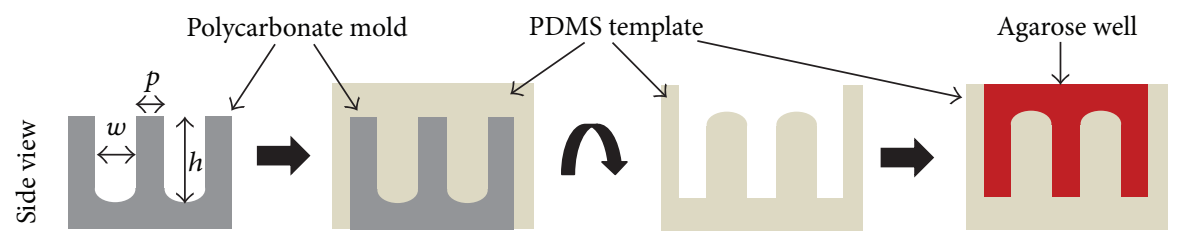

(c)

FIGURE 5: Sketch of cell ring-based approach; (a) schematic of cell seeding and ring self-assembly process; monodisperse cells (black dots) are pipetted into ring-shaped agarose wells; within 24 hours, cells form ring-shaped aggregates (black circles) contracted around center posts; (b) photograph of $2 \mathrm{~mm}$ diameter rat smooth muscle cell rings (arrowhead) in agarose wells; (c) schematic of agarose well fabrication process; silicone elastomer (PDMS) is cured on machined polycarbonate molds to form a template; molten agarose is poured into the PDMS template to form agarose wells; polycarbonate mold dimensions (post diameter, $p$; well width, $w$; and well height, $h$ ) can be modified to make cell rings of different sizes (courtesy of Dr. Marsha W. Rolle, Worcester Polytechnic Institute).

The most relevant and recent (2008-2013) studies on TEVG development without the use of scaffolds are reported in Table 7, focusing on the fabrication method and mechanical and biological performances. Cell sheet-based TEVGs, developed by L'Heureux's group and involved in a clinical trial, are widely described in Section 4.

\section{Clinical Trials of Vascular Tissue Engineering}

Clinical trials were conducted by Shinoka's et al. [52] and L'Heureux's [82] groups using two different types of TEVGs. Although Shin'oka's group did not develop TEVGs for small diameter blood vessel regeneration (ID $=12-24 \mathrm{~mm}$ ), their studies are described in this paragraph because they carried out the first successful clinical trial of TEVGs.

In 2001, Shin'oka et al. [52] performed the first successful clinical trial of a TEVG in humans (25 patients), specifically in the high-flow low-pressure pulmonary venous system of pediatric and young patients. The patients were not treated with long-term antiplatelet and anticoagulation therapy [83]. The investigated TEVGs consisted of a polymeric scaffold made of PGA or PLLA fiber-based meshes coated with a 50:50 copolymer of L-lactide and $\mathcal{\varepsilon}$-caprolactone (PCLA/PGA or PCLA/PLLA) [83]. Specifically, TEVGs were fabricated by pouring and freeze-drying a PCLA solution onto the PGA or PLLA woven mesh (ID = 12-24 mm) [14]. Shin'oka's group designed these scaffolds to improve the poor compliance match with blood vessels and the poor surgical handling properties of PGA fibers [83]. For the first surgeries, grafts were in vitro seeded with autologous vascular cells isolated from peripheral vein biopsies $[52,83,84]$. This procedure was time-consuming, limiting its clinical utility: cell expansion took approximately 60 days and cell cultured onto scaffolds approximately 10 days, increasing the contamination risks. In addition, this methodology demanded an invasive technique for cell harvesting and showed the difficulty to collect healthy cells from diseased patients $[83,84]$. Therefore, another cell type was found to avoid the limitations related to the use of autologous vascular cells. The improved procedure consisted of in vitro scaffold seeding with autologous bone marrow-derived mononuclear cells, isolated from the iliac crest, instead of autologous vascular cells [84]. Bone marrow mononuclear cells could be harvested the same day of the vascular surgery and required a short scaffold incubation time before the implant (2 hours) $[9,84]$. Approximately 2 years after implantation, TEVGs were functional, without any sign of thrombosis, stenosis, obstruction, aneurysm, or calcification $[4,9]$. Approximately 7 years after implantation, the long-term followup showed no mortality related to TEVGs. Nevertheless, $16 \%$ of patients showed TEVG stenosis that was successfully treated with angioplasty and stenting $[4,9,14,83,84]$. This complication was developed in TEVGs with smaller diameter (ID $<18 \mathrm{~mm}$ ) [83]. The clinical trial demonstrated the TEVG growth potential and also some TEVG limitations: long-term graft stenosis $[4,9,14,83,84]$ and lack of mechanical properties necessary for a use as highpressure arterial replacements [5].

L'Heureux's group [82] developed a cell sheet-based technology to generate completely autologous TEVGs and performed a clinical trial for hemodialysis in 10 patients with end-stage renal disease and previous hemodialysis failure. TEVGs were implanted as arteriovenous shunts in the limb that was contralateral to the existing graft, specifically placed in the upper arm, typically between the humeral artery and axillary vein [81]. To fabricate completely autologous TEVGs, dermal fibroblasts were isolated from a skin biopsy and in 


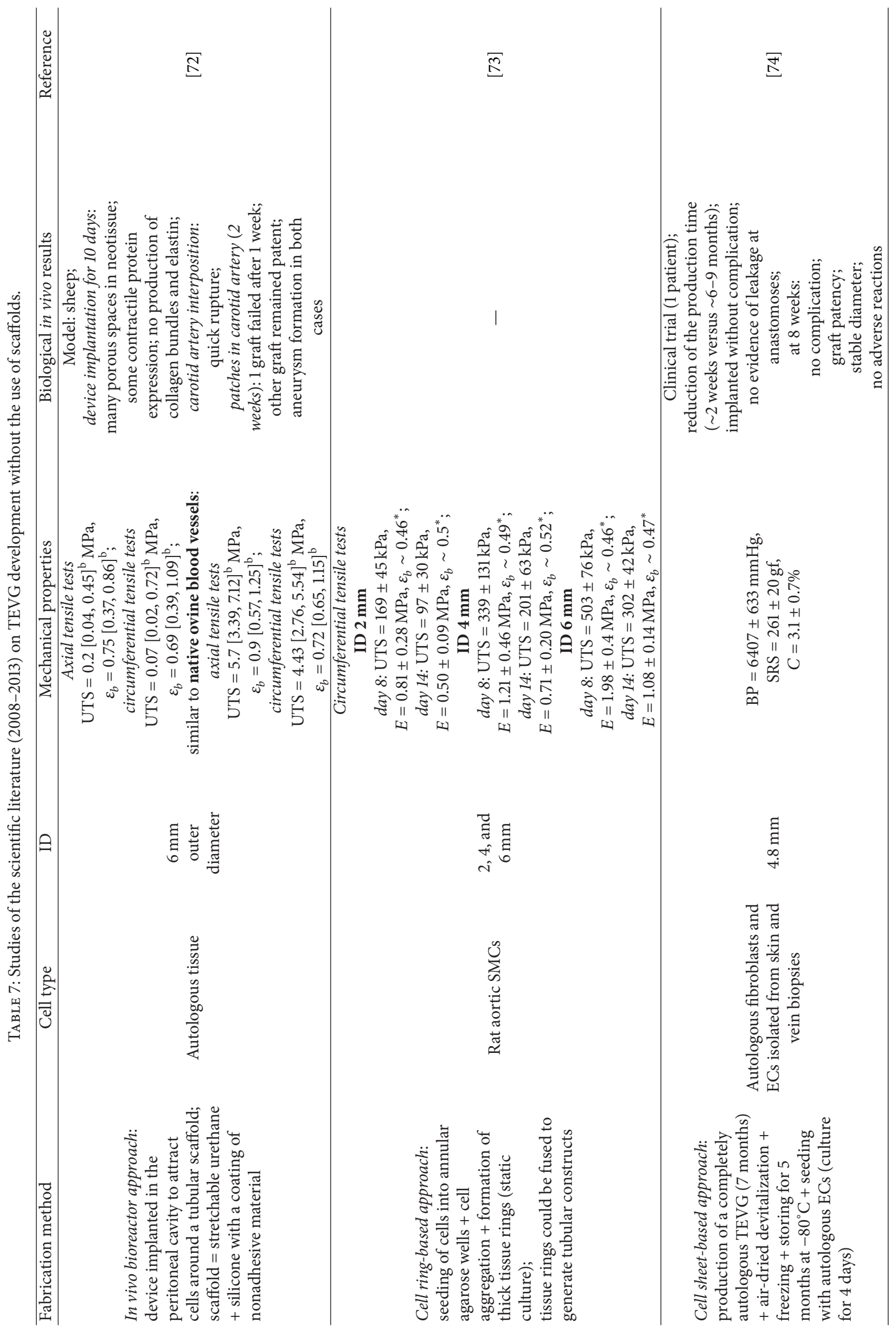




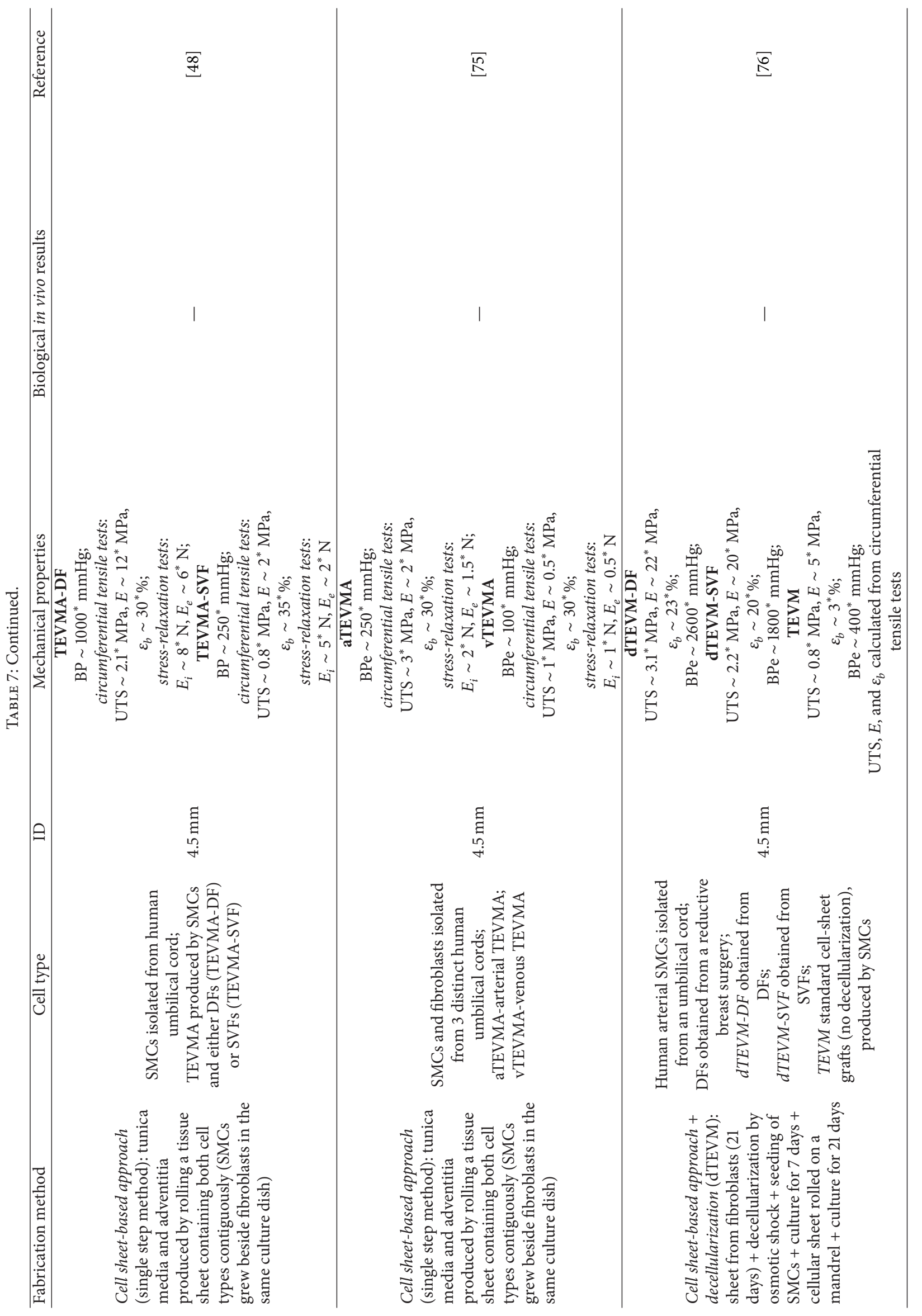




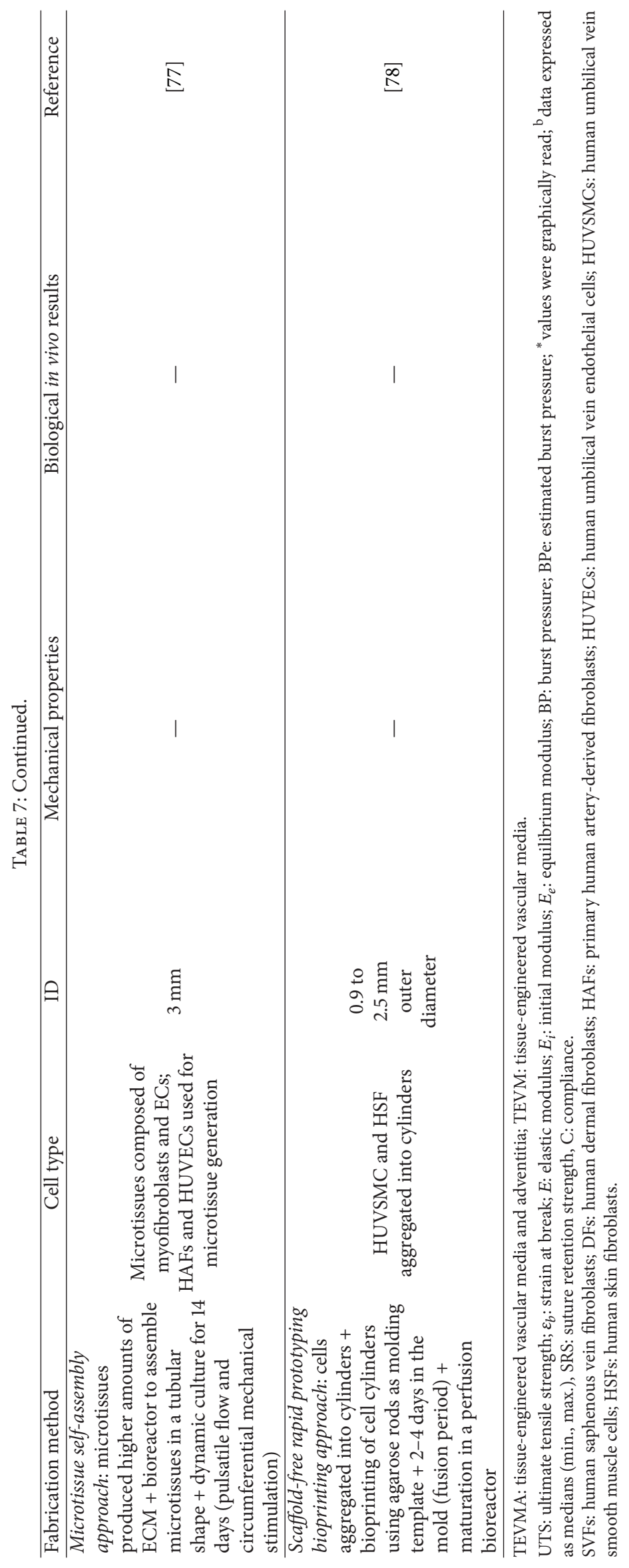


vitro cultured with ascorbic acid, facilitating the production of extracellular matrix proteins $[5,81]$. Approximately 6 weeks after the seeding, fibroblast sheets were detached from culture flasks, wound around a temporary mandrel (diameter $=4.8 \mathrm{~mm}$ ), and led to maturation for approximately 10 weeks to generate a homogenous tissue $[5,81]$. Then, autologous endothelial cells isolated from peripheral vein or endothelial precursors taken from circulating blood were seeded into the TEVG inner layer devitalized by air-drying, few days before surgery [5]. TEVGs required 6 to 9 months of in vitro growth prior to implantation [81]. Primary patency was maintained in 7 of the remaining 9 patients 1 month after implantation and in 5 of the remaining 8 patients 3-6 months after implantation [81]. There were 3 TEVG failures due to thrombosis or aneurysm during the safety phase that was used to evaluate TEVG mechanical stability. In spite of the use of completely autologous grafts, one patient showed a TEVG aneurysm, mediated by an acute immune response that was caused by high levels of immunoglobulin G present in a serum batch during the cell culture $[8,81]$. At implantation, TEVGs exhibited a poor compliance $(3.4 \pm 1.6 \% / 100 \mathrm{mmHg}$, experimental evaluation) in comparison with human internal mammary artery; however, 6 months after implantation the TEVG compliance increased and was equal to $8.8 \pm$ $4.2 \% / 100 \mathrm{mmHg}$ (measured by Doppler ultrasound) [85]. Some challenges are related to L'Heureux's clinical trial; participants were end-stage renal disease patients and TEVGs are subject to repeated puncture and great hemodynamic loads typical of the hemodialysis access $[5,8]$. To date, L'Heureux's group intends to decrease the cost $(\geq \$ 15,000$ per graft [23]), the complexity, and the time for the production of their TEVGs [8]. They performed a first human implant of a devitalized frozen graft in a hemodialysis patient: 5 days prior to surgery, the TEVG was rehydrated and its lumen was seeded with autologous endothelial cells [8]. Five months after implantation the TEVG worked with no evidence of failure [8].

\section{Conclusions and Future Perspectives}

This review is focused on the most relevant and recent advances concerning vascular tissue engineering for small diameter blood vessel applications, specifically the development of TEVGs made of decellularized matrices and natural and/or biodegradable synthetic polymers and their realization without the use of scaffolds. Particular attention is paid to scaffolds made of natural and/or biodegradable synthetic materials, highlighting their advantages and disadvantages and comparing mechanical and biological performances of natural and synthetic materials.

Main failures of ePTFE prosthesis were related to neointimal hyperplasia, remarkable calcification, thrombosis, and foreign body reaction [60]. During clinical trials or in vivo animal tests, TEVGs often showed the same failure causes of ePTFE prostheses (Tables 3-7 and Section 4). The challenge of vascular tissue engineering still remains the development of TEVGs that are able to regenerate a functional endothelium and exhibit mechanical properties similar to native blood vessels. Although completely autologous TEVGs have reached promising results in clinical trials, the development of readily available TEVGs characterized by an economical feasibility still remains a major challenge. In fact, the fabrication of completely biological TEVGs without the use of scaffolds requires long time and high cost of manufacturing (Section 2.6).

Among the different approaches based on the use of scaffolds, the direct implantation of cell-seeded scaffolds without the use of bioreactors simplifies the procedure and reduces the cost related to the use of bioreactors. This method is based on the concept that the cells seeded in scaffold play a key role in the recruitment of the host cells for in vivo tissue regeneration, as shown by Shin'oka's group. The implantation of acellular scaffolds for in situ tissue regeneration by the host would avoid the limits correlated to the in vitro cellularization of scaffolds, specifically the cell choice and expansion, and the use of a bioreactor that is time-consuming and technical complex due to the mandatory application of Good Manufacturing Practice (GMP, EudraLex-Volume 4) for the clinical use. Therefore, both of these approaches lead or would lead to off-of-the-shelf scaffolds for the regeneration of small diameter blood vessels, considerably simplifying the procedure for fabrication of TEVGs and reducing the cost and the time of manufacturing.

Among all the available materials for small diameter blood vessel regeneration, hybrid scaffolds exhibit promising and tailorable results due to the combination of appropriate mechanical properties of synthetic polymers with excellent biological performances of natural polymers (Section 2.5). Furthermore, an important perspective would be the direct introduction of antiinflammatory and antiproliferative drugs in TEVGs, due to the better knowledge of molecular pathogenesis of artery disease.

\section{Conflict of Interests}

The authors declare that there is no conflict of interests regarding the publication of this paper.

\section{Acknowledgments}

The work was supported by Cariplo Foundation funds 2007 to G. Freddi (Project no. 2007-5457). The authors would like to thank Dr. Marsha W. Rolle for the useful discussion and comments.

\section{References}

[1] World Health Organization, "Cardiovascular diseases," Fact Sheet No. 317, 2012.

[2] P. A. Heidenreich, J. G. Trogdon, O. A. Khavjou et al., "Forecasting the future of cardiovascular disease in the United States: a policy statement from the American heart association," Circulation, vol. 123, no. 8, pp. 933-944, 2011.

[3] L. Bordenave, P. Menu, and C. Baquey, "Developments towards tissue-engineered, small-diameter arterial substitutes," Expert Review of Medical Devices, vol. 5, no. 3, pp. 337-347, 2008.

[4] A. Rathore, M. Cleary, Y. Naito, K. Rocco, and C. Breuer, "Development of tissue engineered vascular grafts and application of 
nanomedicine," Wiley Interdisciplinary Reviews: Nanomedicine and Nanobiotechnology, vol. 4, no. 3, pp. 257-272, 2012.

[5] N. L'Heureux, N. Dusserre, A. Marini, S. Garrido, L. de la Fuente, and T. McAllister, "Technology Insight: the evolution of tissue-engineered vascular grafts-from research to clinical practice," Nature Clinical Practice Cardiovascular Medicine, vol. 4, no. 7, pp. 389-395, 2007.

[6] F. Couet, N. Rajan, and D. Mantovani, "Macromolecular biomaterials for scaffold-based vascular tissue engineering," Macromolecular Bioscience, vol. 7, no. 5, pp. 701-718, 2007.

[7] S. Goldman, K. Zadina, T. Moritz et al., "Long-term patency of saphenous vein and left internal mammary artery grafts after coronary artery bypass surgery: results from a department of veterans affairs cooperative study," Journal of the American College of Cardiology, vol. 44, no. 11, pp. 2149-2156, 2004.

[8] M. Peck, D. Gebhart, N. Dusserre, T. N. McAllister, and N. L'Heureux, "The evolution of vascular tissue engineering and current state of the art," Cells Tissues Organs, vol. 195, no. 1-2, pp. 144-158, 2011.

[9] E. W. Dean, B. Udelsman, and C. K. Breuer, "Current advances in the translation of vascular tissue engineering to the treatment of pediatric congenital heart disease," Yale Journal of Biology and Medicine, vol. 85, no. 2, pp. 229-238, 2012.

[10] L. V. Thomas, V. Lekshmi, and P. D. Nair, "Tissue engineered vascular grafts-preclinical aspects," International Journal of Cardiology, vol. 167, no. 4, pp. 1091-1100, 2013.

[11] M. S. Conte, M. J. Mann, H. F. Simosa, K. K. Rhynhart, and R. C. Mulligan, "Genetic interventions for vein bypass graft disease: a review," Journal of Vascular Surgery, vol. 36, no. 5, pp. 1040-1052, 2002.

[12] M. Deutsch, J. Meinhart, P. Zilla et al., "Long-term experience in autologous in vitro endothelialization of infrainguinal ePTFE grafts," Journal of Vascular Surgery, vol. 49, no. 2, pp. 352-362, 2009.

[13] M. S. Baguneid, A. M. Seifalian, H. J. Salacinski, D. Murray, G. Hamilton, and M. G. Walker, "Tissue engineering of blood vessels," The British Journal of Surgery, vol. 93, no. 3, pp. 282290, 2006.

[14] Y. Naito, T. Shinoka, D. Duncan et al., "Vascular tissue engineering: towards the next generation vascular grafts," Advanced Drug Delivery Reviews, vol. 63, no. 4, pp. 312-323, 2011.

[15] A. V. Piterina, A. J. Cloonan, C. L. Meaney et al., "ECMbased materials in cardiovascular applications: inherent healing potential and augmentation of native regenerative processes," International Journal of Molecular Sciences, vol. 10, no. 10, pp. 4375-4417, 2009.

[16] J. J. Song and H. C. Ott, "Organ engineering based on decellularized matrix scaffolds," Trends in Molecular Medicine, vol. 17, no. 8, pp. 424-432, 2011.

[17] S. F. Badylak, D. O. Freytes, and T. W. Gilbert, "Extracellular matrix as a biological scaffold material: structure and function," Acta Biomaterialia, vol. 5, no. 1, pp. 1-13, 2009.

[18] A. F. Pellegata, M. A. Asnaghi, I. Stefani et al., "Detergentenzymatic decellularization of swine blood vessels: insight on mechanical properties for vascular tissue engineering," BioMed Research International, vol. 2013, Article ID 918753, 8 pages, 2013.

[19] T. Huynh, G. Abraham, J. Murray, K. Brockbank, P. Hagen, and S. Sullivan, "Remodeling of an acellular collagen graff into a physiologically responsive neovessel," Nature Biotechnology, vol. 17, no. 11, pp. 1083-1086, 1999.
[20] A. Bader, G. Steinhoff, K. Strobl et al., "Engineering of human vascular aortic tissue based on a xenogeneic starter matrix," Transplantation, vol. 70, no. 1, pp. 7-14, 2000.

[21] S. Kaushal, G. E. Amiel, K. J. Guleserian et al., "Functional small-diameter neovessels created using endothelial progenitor cells expanded ex vivo," Nature Medicine, vol. 7, no. 9, pp. 10351040, 2001.

[22] S. L. M. Dahl, J. Koh, V. Prabhakar, and L. E. Niklason, "Decellularized native and engineered arterial scaffolds for transplantation," Cell Transplantation, vol. 12, no. 6, pp. 659666, 2003.

[23] S. L. Dahl, A. P. Kypson, J. H. Lawson et al., "Readily available tissue-engineered vascular grafts," Science Translational Medicine, vol. 3, no. 68, Article ID 68ra9, 2011.

[24] J. F. Mano, G. A. Silva, H. S. Azevedo et al., "Natural origin biodegradable systems in tissue engineering and regenerative medicine: present status and some moving trends," Journal of the Royal Society Interface, vol. 4, no. 17, pp. 999-1030, 2007.

[25] D. Pankajakshan and D. K. Agrawal, "Scaffolds in tissue engineering of blood vessels," Canadian Journal of Physiology and Pharmacology, vol. 88, no. 9, pp. 855-873, 2010.

[26] S. G. Wise, M. J. Byrom, A. Waterhouse, P. G. Bannon, M. K. C. Ng, and A. S. Weiss, "A multilayered synthetic human elastin/polycaprolactone hybrid vascular graft with tailored mechanical properties," Acta Biomaterialia, vol. 7, no. 1, pp. 295303, 2011.

[27] K. A. McKenna, M. T. Hinds, R. C. Sarao et al., "Mechanical property characterization of electrospun recombinant human tropoelastin for vascular graft biomaterials," Acta Biomaterialia, vol. 8, no. 1, pp. 225-233, 2012.

[28] B. Zavan, V. Vindigni, S. Lepidi et al., "Neoarteries grown in vivo using a tissue-engineered hyaluronan-based scaffold," FASEB Journal, vol. 22, no. 8, pp. 2853-2861, 2008.

[29] S. W. Jordan, C. A. Haller, R. E. Sallach, R. P. Apkarian, S. R. Hanson, and E. L. Chaikof, "The effect of a recombinant elastinmimetic coating of an ePTFE prosthesis on acute thrombogenicity in a baboon arteriovenous shunt," Biomaterials, vol. 28, no. 6, pp. 1191-1197, 2007.

[30] K. A. Woodhouse, P. Klement, V. Chen et al., "Investigation of recombinant human elastin polypeptides as non-thrombogenic coatings," Biomaterials, vol. 25, no. 19, pp. 4543-4553, 2004.

[31] C. Vepari and D. L. Kaplan, "Silk as a biomaterial," Progress in Polymer Science, vol. 32, no. 8-9, pp. 991-1007, 2007.

[32] R. L. Horan, K. Antle, A. L. Collette et al., "In vitro degradation of silk fibroin," Biomaterials, vol. 26, no. 17, pp. 3385-3393, 2005.

[33] B. Marelli, M. Achilli, A. Alessandrino et al., "Collagenreinforced electrospun silk fibroin tubular construct as small calibre vascular graft," Macromolecular Bioscience, vol. 12, no. 11, pp. 1566-1574, 2012.

[34] C. B. Weinberg and E. Bell, "A blood vessel model constructed from collagen and cultured vascular cells," Science, vol. 231, no. 4736, pp. 397-400, 1986.

[35] D. Seliktar, R. A. Black, R. P. Vito, and R. M. Nerem, “Dynamic mechanical conditioning of collagen-gel blood vessel constructs induces remodeling in vitro," Annals of Biomedical Engineering, vol. 28, no. 4, pp. 351-362, 2000.

[36] E. D. Grassl, T. R. Oegema, and R. T. Tranquillo, "Fibrin as an alternative biopolymer to type-I collagen for the fabrication of a media equivalent," Journal of Biomedical Materials Research, vol. 60, no. 4, pp. 607-612, 2002. 
[37] E. D. Grassl, T. R. Oegema, and R. T. Tranquillo, "A fibrin-based arterial media equivalent," Journal of Biomedical Materials Research A, vol. 66, no. 3, pp. 550-561, 2003.

[38] D. D. Swartz, J. A. Russell, and S. T. Andreadis, "Engineering of fibrin-based functional and implantable small-diameter blood vessels," The American Journal of Physiology-Heart and Circulatory Physiology, vol. 288, no. 3, pp. H1451-H1460, 2005.

[39] L. Yao, J. Liu, and S. T. Andreadis, "Composite fibrin scaffolds increase mechanical strength and preserve contractility of tissue engineered blood vessels," Pharmaceutical Research, vol. 25, no. 5, pp. 1212-1221, 2008.

[40] Z. H. Syedain, L. A. Meier, J. W. Bjork, A. Lee, and R. T. Tranquillo, "Implantable arterial grafts from human fibroblasts and fibrin using a multi-graft pulsed flow-stretch bioreactor with noninvasive strength monitoring," Biomaterials, vol. 32, no. 3, pp. 714-722, 2011

[41] H. J. Salacinski, S. Goldner, A. Giudiceandrea et al., "The mechanical behavior of vascular grafts: a review," Journal of Biomaterials Applications, vol. 15, no. 3, pp. 241-278, 2001.

[42] M. Zidi and M. Cheref, "Mechanical analysis of a prototype of small diameter vascular prosthesis: numerical simulations," Computers in Biology and Medicine, vol. 33, no. 1, pp. 65-75, 2003.

[43] S. Koch, T. C. Flanagan, J. S. Sachweh et al., "Fibrin-polylactidebased tissue-engineered vascular graft in the arterial circulation," Biomaterials, vol. 31, no. 17, pp. 4731-4739, 2010.

[44] K. Kim, M. Yu, X. Zong et al., "Control of degradation rate and hydrophilicity in electrospun non-woven poly(D,L-lactide) nanofiber scaffolds for biomedical applications," Biomaterials, vol. 24, no. 27, pp. 4977-4985, 2003.

[45] S. J. Lee, J. Liu, S. H. Oh, S. Soker, A. Atala, and J. J. Yoo, "Development of a composite vascular scaffolding system that withstands physiological vascular conditions," Biomaterials, vol. 29, no. 19, pp. 2891-2898, 2008.

[46] S. de Valence, J. Tille, D. Mugnai et al., "Long term performance of polycaprolactone vascular grafts in a rat abdominal aorta replacement model," Biomaterials, vol. 33, no. 1, pp. 38-47, 2012.

[47] Y. Wang, G. A. Ameer, B. J. Sheppard, and R. Langer, "A tough biodegradable elastomer," Nature Biotechnology, vol. 20, no. 6, pp. 602-606, 2002.

[48] R. Gauvin, T. Ahsan, D. Larouche et al., "A novel single-step self-assembly approach for the fabrication of tissue-engineered vascular constructs," Tissue Engineering A, vol. 16, no. 5, pp. 1737-1747, 2010.

[49] D. J. Mooney, C. L. Mazzoni, C. Breuer et al., "Stabilized polyglycolic acid fibre-based tubes for tissue engineering," Biomaterials, vol. 17, no. 2, pp. 115-124, 1996.

[50] L. E. Niklason, J. Gao, W. M. Abbott et al., "Functional arteries grown in vitro," Science, vol. 284, no. 5413, pp. 489-493, 1999.

[51] D. Shum-Tim, U. Stock, J. Hrkach et al., "Tissue engineering of autologous aorta using a new biodegradable polymer," Annals of Thoracic Surgery, vol. 68, no. 6, pp. 2298-2305, 1999.

[52] T. Shin'oka, Y. Imai, and Y. Ikada, "Transplantation of a tissueengineered pulmonary artery," The New England Journal of Medicine, vol. 344, no. 7, pp. 532-533, 2001.

[53] S. de Valence, J. C. Tille, J. P. Giliberto et al., "Advantages of bilayered vascular grafts for surgical applicability and tissue regeneration," Acta Biomaterialia, vol. 8, no. 11, pp. 3914-3920, 2012.

[54] F. Kuwabara, Y. Narita, A. Yamawaki-Ogata et al., "Long-term results of tissue-engineered small-caliber vascular grafts in a rat carotid arterial replacement model," Journal of Artificial Organs, vol. 15, no. 4, pp. 399-405, 2012.

[55] K. Iwasaki, K. Kojima, S. Kodama et al., "Bioengineered three-layered robust and elastic artery using hemodynamicallyequivalent pulsatile bioreactor," Circulation, vol. 118, no. 14, supplement, pp. S52-S57, 2008.

[56] W. Wu, R. A. Allen, and Y. Wang, "Fast-degrading elastomer enables rapid remodeling of a cell-free synthetic graft into a neoartery," Nature Medicine, vol. 18, no. 7, pp. 1148-1153, 2012.

[57] J. D. Roh, G. N. Nelson, M. P. Brennan et al., "Small-diameter biodegradable scaffolds for functional vascular tissue engineering in the mouse model," Biomaterials, vol. 29, no. 10, pp. 14541463, 2008.

[58] T. Uchida, S. Ikeda, H. Oura et al., "Development of biodegradable scaffolds based on patient-specific arterial configuration," Journal of Biotechnology, vol. 133, no. 2, pp. 213-218, 2008.

[59] W. D. Lü, M. Zhang, Z. S. Wu, and T. H. Hu, "Work in progress report-congenital decellularized and photooxidatively crosslinked bovine jugular veins as potential tissue engineering scaffolds," Interactive Cardiovascular and Thoracic Surgery, vol. 8, no. 3, pp. 301-305, 2009.

[60] A. Assmann, C. Delfs, H. Munakata et al., "Acceleration of autologous in vivo recellularization of decellularized aortic conduits by fibronectin surface coating," Biomaterials, vol. 34, no. 25, pp. 6015-6026, 2013.

[61] B. Brown, K. Lindberg, J. Reing, D. B. Stolz, and S. F. Badylak, "The basement membrane component of biologic scaffolds derived from extracellular matrix," Tissue Engineering, vol. 12, no. 3, pp. 519-526, 2006.

[62] A. V. Piterina, A. Callanan, L. Davis, C. Meaney, M. Walsh, and T. M. McGloughlin, "Extracellular matrices as advanced scaffolds for vascular tissue engineering," Bio-Medical Materials and Engineering, vol. 19, no. 4-5, pp. 333-348, 2009.

[63] S. W. Cho, I. K. Kim, J. M. Kang et al., "Evidence for in vivo growth potential and vascular remodeling of tissue-engineered artery," Tissue Engineering A, vol. 15, no. 4, pp. 901-912, 2009.

[64] L. Gui, A. Muto, S. A. Chan, C. K. Breuer, and L. E. Niklason, "Development of decellularized human umbilical arteries as small-diameter vascular grafts," Tissue Engineering A, vol. 15, no. 9, pp. 2665-2676, 2009.

[65] B. Marelli, A. Alessandrino, S. Farè, G. Freddi, D. Mantovani, and M. C. Tanzi, "Compliant electrospun silk fibroin tubes for small vessel bypass grafting," Acta Biomaterialia, vol. 6, no. 10, pp. 4019-4026, 2010.

[66] M. Lovett, G. Eng, J. A. Kluge, C. Cannizzaro, G. VunjakNovakovic, and D. L. Kaplan, "Tubular silk scaffolds for small diameter vascular grafts," Organogenesis, vol. 6, no. 4, pp. 217224, 2010.

[67] C. Wang, L. Cen, S. Yin et al., "A small diameter elastic blood vessel wall prepared under pulsatile conditions from polyglycolic acid mesh and smooth muscle cells differentiated from adipose-derived stem cells," Biomaterials, vol. 31, no. 4, pp. 621-630, 2010.

[68] M. J. McClure, S. A. Sell, D. G. Simpson, B. H. Walpoth, and G. L. Bowlin, "A three-layered electrospun matrix to mimic native arterial architecture using polycaprolactone, elastin, and collagen: a preliminary study," Acta Biomaterialia, vol. 6, no. 7, pp. 2422-2433, 2010.

[69] T. Yokota, H. Ichikawa, G. Matsumiya et al., "In situ tissue regeneration using a novel tissue-engineered, small-caliber vascular graft without cell seeding," Journal of Thoracic and Cardiovascular Surgery, vol. 136, no. 4, pp. 900-907, 2008. 
[70] B. W. Tillman, S. K. Yazdani, S. J. Lee, R. L. Geary, A. Atala, and J. J. Yoo, "The in vivo stability of electrospun polycaprolactonecollagen scaffolds in vascular reconstruction," Biomaterials, vol. 30, no. 4, pp. 583-588, 2009.

[71] W. He, Z. Ma, W. E. Teo et al., "Tubular nanofiber scaffolds for tissue engineered small-diameter vascular grafts," Journal of Biomedical Materials Research A, vol. 90, no. 1, pp. 205-216, 2009.

[72] P. Stickler, G. de Visscher, L. Mesure et al., "Cyclically stretching developing tissue in vivo enhances mechanical strength and organization of vascular grafts," Acta Biomaterialia, vol. 6, no. 7, pp. 2448-2456, 2010.

[73] T. A. Gwyther, J. Z. Hu, A. G. Christakis et al., "Engineered vascular tissue fabricated from aggregated smooth muscle cells," Cells Tissues Organs, vol. 194, no. 1, pp. 13-24, 2011.

[74] W. Wystrychowski, L. Cierpka, K. Zagalski et al., "Case study: first implantation of a frozen, devitalized tissueengineered vascular graft for urgent hemodialysis access," Journal of Vascular Access, vol. 12, no. 1, pp. 67-70, 2011.

[75] R. Gauvin, M. Guillemette, T. Galbraith et al., "Mechanical properties of tissue-engineered vascular constructs produced using arterial or venous cells," Tissue Engineering A, vol. 17, no. 15-16, pp. 2049-2059, 2011.

[76] J. M. Bourget, R. Gauvin, D. Larouche et al., "Human fibroblastderived ECM as a scaffold for vascular tissue engineering," Biomaterials, vol. 33, no. 36, pp. 9205-9213, 2012.

[77] J. M. Kelm, V. Lorber, J. G. Snedeker et al., "A novel concept for scaffold-free vessel tissue engineering: self-assembly of microtissue building blocks," Journal of Biotechnology, vol. 148, no. 1, pp. 46-55, 2010.

[78] C. Norotte, F. S. Marga, L. E. Niklason, and G. Forgacs, "Scaffold-free vascular tissue engineering using bioprinting," Biomaterials, vol. 30, no. 30, pp. 5910-5917, 2009.

[79] E. Pektok, B. Nottelet, J. Tille et al., "Degradation and healing characteristics of small-diameter poly( $\varepsilon$-caprolactone) vascular grafts in the rat systemic arterial circulation," Circulation, vol. 118, no. 24, pp. 2563-2570, 2008.

[80] A. de Mel, C. Bolvin, M. Edirisinghe, G. Hamilton, and A. M. Seifalian, "Development of cardiovascular bypass grafts: endothelialization and applications of nanotechnology," Expert Review of Cardiovascular Therapy, vol. 6, no. 9, pp. 1259-1277, 2008.

[81] T. N. McAllister, M. Maruszewski, S. A. Garrido et al., "Effectiveness of haemodialysis access with an autologous tissueengineered vascular graft: a multicentre cohort study," The Lancet, vol. 373, no. 9673, pp. 1440-1446, 2009.

[82] N. L'Heureux, T. N. McAllister, and L. M. de la Fuente, "Tissueengineered blood vessel for adult arterial revascularization," The New England Journal of Medicine, vol. 357, no. 14, pp. 1451-1453, 2007.

[83] T. Shinoka and C. Breuer, "Tissue-engineered blood vessels in pediatric cardiac surgery," Yale Journal of Biology and Medicine, vol. 81, no. 4, pp. 161-166, 2008.

[84] M. A. Cleary, E. Geiger, C. Grady, C. Best, Y. Naito, and C. Breuer, "Vascular tissue engineering: the next generation," Trends in Molecular Medicine, vol. 18, no. 7, pp. 394-404, 2012.

[85] G. Konig, T. N. McAllister, N. Dusserre et al., "Mechanical properties of completely autologous human tissue engineered blood vessels compared to human saphenous vein and mammary artery," Biomaterials, vol. 30, no. 8, pp. 1542-1550, 2009. 


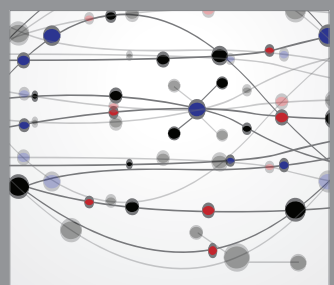

The Scientific World Journal
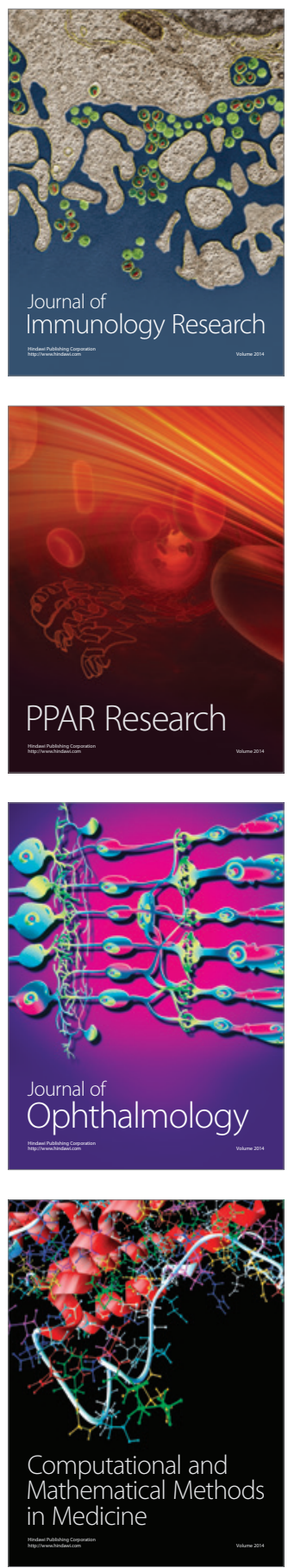

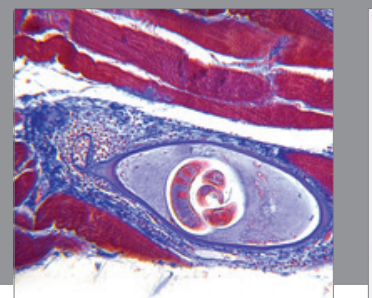

Gastroenterology

Research and Practice
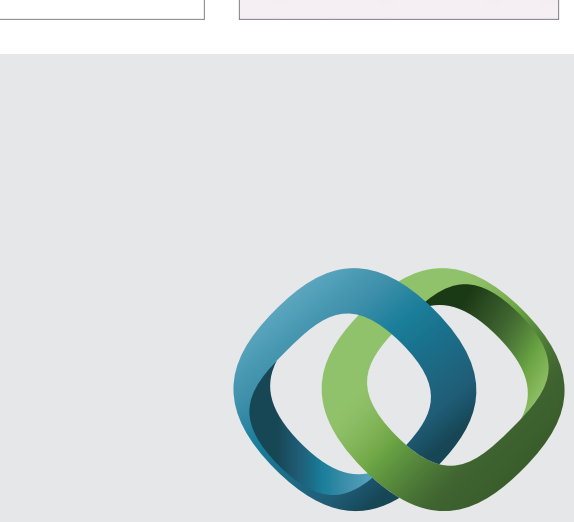

\section{Hindawi}

Submit your manuscripts at

http://www.hindawi.com
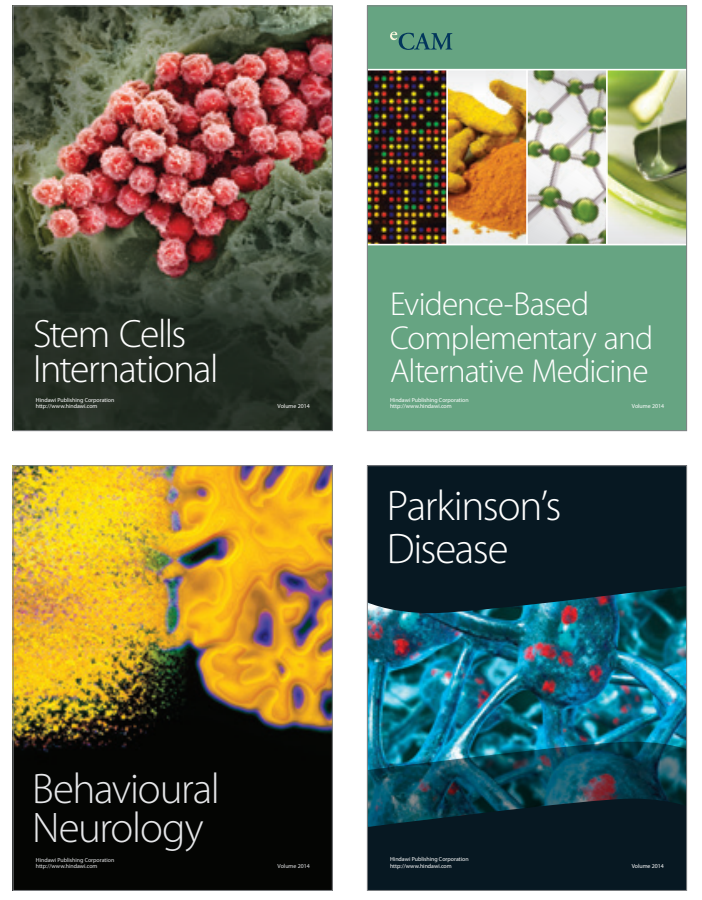
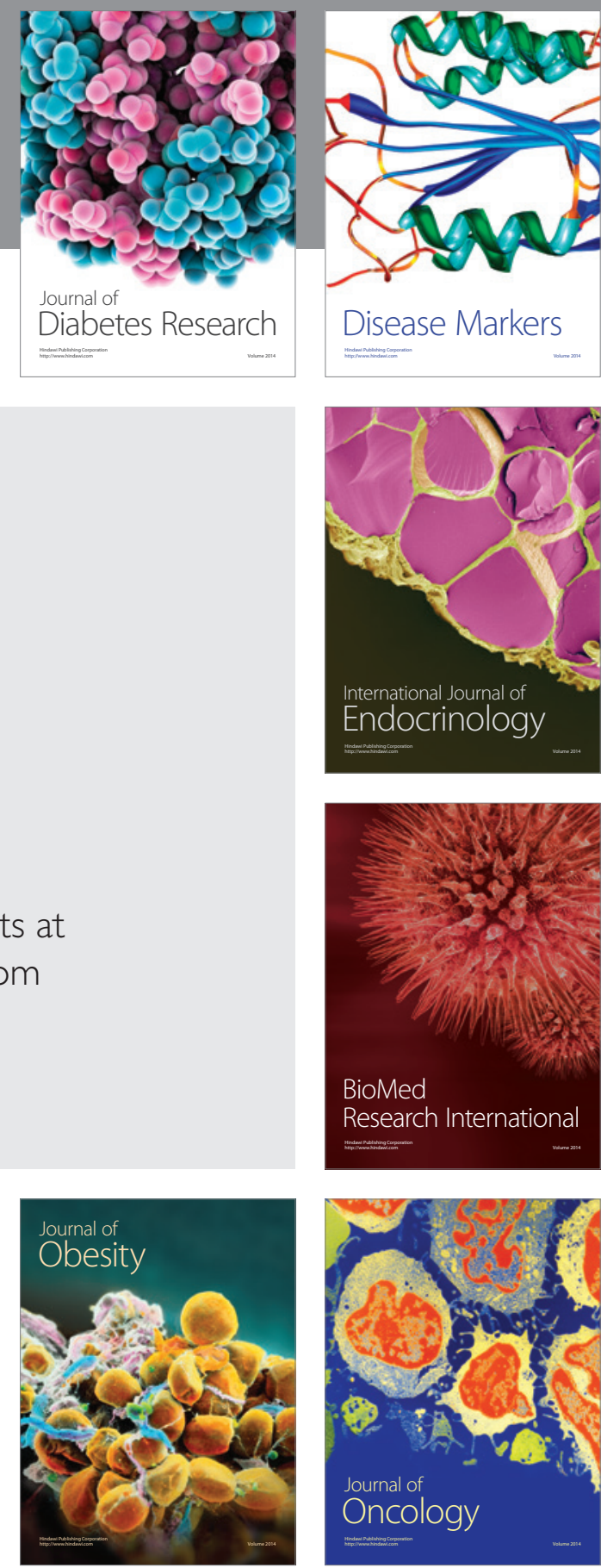

Disease Markers
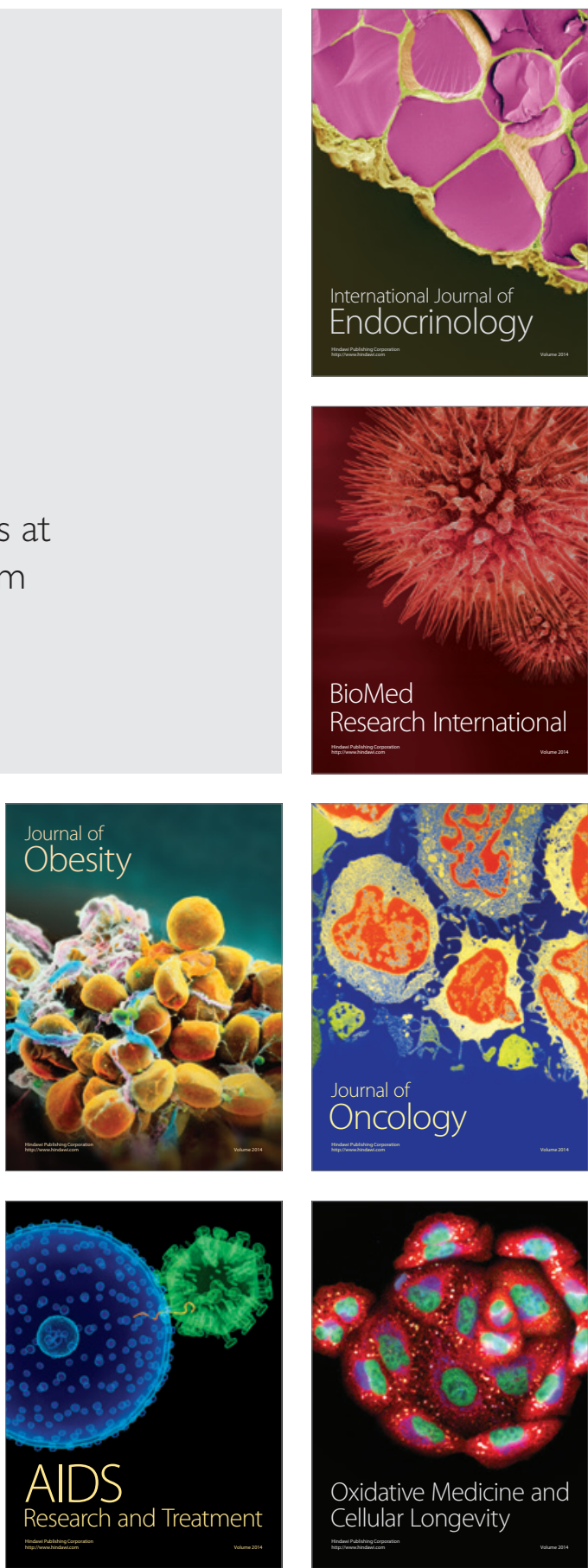